\title{
GPER is involved in the stimulatory effects of aldosterone in breast cancer cells and breast tumor-derived endothelial cells
}

\author{
Damiano Cosimo Rigiracciolo ${ }^{1}$, Andrea Scarpelli' ${ }^{1}$, Rosamaria Lappano ${ }^{1}$, Assunta \\ Pisano ${ }^{1}$, Maria Francesca Santolla ${ }^{1}$, Silvia Avino ${ }^{1}$, Paola De Marco ${ }^{1}$, Benedetta \\ Bussolati ${ }^{2}$, Marcello Maggiolini ${ }^{1}$ and Ernestina Marianna De Francesco ${ }^{1}$ \\ ${ }^{1}$ Department of Pharmacy, Health and Nutritional Sciences, University of Calabria, Rende, Italy \\ 2 Department of Molecular Biotechnology and Health Sciences, University of Torino, Turin, Italy \\ Correspondence to: Marcello Maggiolini, email: marcellomaggiolini@yahoo.it \\ Rosamaria Lappano, email: lappanorosamaria@yahoo.it \\ Keywords: GPER, aldosterone, mineralcorticoid receptor, breast cancer cells, breast tumor-derived endothelial cells, Pathology \\ Section \\ Received: September 01,2015 Accepted: November 22, $2015 \quad$ Published: December 05, 2015
}

\section{ABSTRACT}

\begin{abstract}
Aldosterone induces relevant effects binding to the mineralcorticoid receptor (MR), which acts as a ligand-gated transcription factor. Alternate mechanisms can mediate the action of aldosterone such as the activation of epidermal growth factor receptor (EGFR), MAPK/ERK, transcription factors and ion channels. The G-protein estrogen receptor (GPER) has been involved in the stimulatory effects of estrogenic signalling in breast cancer. GPER has been also shown to contribute to certain responses to aldosterone, however the role played by GPER and the molecular mechanisms implicated remain to be fully understood. Here, we evaluated the involvement of GPER in the stimulatory action exerted by aldosterone in breast cancer cells and breast tumor derived endothelial cells (B-TEC). Competition assays, gene expression and silencing studies, immunoblotting and immunofluorescence experiments, cell proliferation and migration were performed in order to provide novel insights into the role of GPER in the aldosterone-activated signalling. Our results demonstrate that aldosterone triggers the EGFR/ERK transduction pathway in a MRand GPER-dependent manner. Aldosterone does not bind to GPER, it however induces the direct interaction between MR and GPER as well as between GPER and EGFR. Next, we ascertain that the up-regulation of the $\mathrm{Na}^{+} / \mathrm{H}^{+}$exchanger-1 (NHE-1) induced by aldosterone involves MR and GPER. Biologically, both MR and GPER contribute to the proliferation and migration of breast and endothelial cancer cells mediated by NHE-1 upon aldosterone exposure. Our data further extend the current knowledge on the molecular mechanisms through which GPER may contribute to the stimulatory action elicited by aldosterone in breast cancer.
\end{abstract}

\section{INTRODUCTION}

Aldosterone elicits multiple biological effects binding to the mineralcorticoid receptor (MR), which acts as a ligand-gated transcription factor [1]. In addition, rapid aldosterone signalling involves alternate mechanisms that include the activation of transduction pathways like tyrosine kinase c-Src, epidermal growth factor receptor (EGFR) and MAPK/ERK cascade [2-4]. Aldosterone is a key component of the renin-angiotensin-aldosterone system (RAAS), which is mainly implicated in maintaining salt and water balance toward the regulation of systemic blood pressure [5]. In addition, aldosterone activates ionic membrane transporters as the $\mathrm{Na}^{+} / \mathrm{H}^{+}$exchanger (NHE1) and $\mathrm{Na}^{+} / \mathrm{HCO}_{3}^{-}$cotransporter (NBC), which regulate the cellular $\mathrm{pH}$ and volume [6-7]. Aldosterone has been also involved in diverse cardio-metabolic diseases as it triggers inflammatory and fibrotic responses in both heart and vessels [8-11]. Recent studies have suggested that aldosterone/MR signalling may contribute to the progression of certain types of tumor [12-13]. For instance, it has been shown that aldosterone stimulates 
the survival and proliferation of renal carcinoma cells by upregulating K-RAS and the activation of the Akt and Raf pathways [12]. Moreover, an aldosterone blocker inhibited the growth of hepatocellular carcinoma and angiogenesis both in vitro and in vivo [13].

The G-protein estrogen receptor namely GPER mediates several pathophysiological functions in the cardiovascular, immune and central nervous systems, glucose and fat metabolism [14]. In addition, our and other previous studies have largely demonstrated that estrogenic GPER signalling elicits stimulatory effects in cancer cells and tumor microenvironment toward cancer progression [14-19]. In this regard, it has been reported that GPER activation triggers diverse transduction pathways involved in the proliferation, invasion and migration of tumor cells, including the epidermal growth factor receptor (EGFR), the MAPK/ERK and PI3K/ AKT transduction cascades, $\mathrm{Ca}^{2+}$ mobilization and cAMP production [20-27]. Numerous endogenous, environmental and newly synthesized molecules have been shown to trigger relevant GPER-mediated responses in different cell contexts [28-36]. Aldosterone has been recently suggested to act through GPER in diverse models, including the cardiovascular and renal systems [6, 37-40]. For instance, it was demonstrated that GPER is involved in important effects exerted by aldosterone on vascular endothelial cells, cardiac vagal tone and connecting tubule glomerular feedback [37-40]. These observations have pointed out the potential of GPER to contribute to the aldosterone action, however the effective role played by GPER and the molecular mechanisms implicated are controversial as pharmacologic criteria for considering GPER as an aldosterone receptor have been not adequately fulfilled [41-43].

In the framework of the aforementioned observations, the current study provides novel insights into the role of GPER in mediating the action of aldosterone in breast tumor. In particular, our data show that a functional cross-talk between MR and GPER may occur upon aldosterone treatment leading to stimulatory effects in both breast cancer cells and endothelial cells obtained from breast malignancies.

\section{RESULTS}

\section{Aldosterone activates the EGFR/ERK transduction pathway and induces the interaction between MR and GPER}

We began our study evaluating whether aldosterone could be able to activate the EGFR/ERK transduction signalling in $\mathrm{SkBr} 3$ breast cancer cells and B-TEC breast tumor-derived endothelial cells, which were used as model systems. Both cell types express MR and GPER but not
ER $\alpha$ (Supplementary Figure 1). Of note, pM aldosterone concentrations induced the phosphorylation of EGFR and ERK1/2 in both SkBr3 cells and B-TEC (Figure 1A-1D), though these effects were no longer evident silencing the expression of MR (Figure 1E-1J). Recently, it has been reported that GPER contributes to aldosterone action although the mechanisms involved remain to be fully understood [6, 38-44]. In this vein, we therefore performed saturation curves and scatchard plot analyses using as radiotracers the GPER ligand $\left[{ }^{3} \mathrm{H}\right] \mathrm{E} 2$ [28, 31-32, 34-36] and the MR ligand $\left[{ }^{3} \mathrm{H}\right]$ aldosterone. $\left[{ }^{3} \mathrm{H}\right] \mathrm{E} 2$ showed an estimated Bmax corresponding to $6799 \pm 707.8 \mathrm{cpm} / 1 \times$ $10^{5} \mathrm{SkBr} 3$ cells and an estimated $\mathrm{Kd}$ corresponding to 8.16 $\pm 1.70 \mathrm{nM}$ (Figure 2A), whereas $\left[{ }^{3} \mathrm{H}\right]$ aldosterone showed an estimated Bmax corresponding to $2159 \pm 229.2 \mathrm{cpm} / 1$ $\times 10^{5} \mathrm{SkBr} 3$ cells and an estimated $\mathrm{Kd}$ corresponding to $0.42 \pm 0.08 \mathrm{nM}$ (Figure 2B). In competition assays, E2 but not aldosterone displaced $\left[{ }^{3} \mathrm{H}\right] \mathrm{E} 2$ (Figure $2 \mathrm{C}$ ), while aldosterone but not E2 displaced [ $\left.{ }^{3} \mathrm{H}\right]$ Aldosterone (Figure 2D). Collectively, these findings argue that in $\mathrm{SkBr} 3$ cells aldosterone is not able to displace $\left[{ }^{3} \mathrm{H}\right] \mathrm{E} 2$, which was used as a GPER radioligand.

In order to gain further insights into the role of GPER in certain biological responses to aldosterone, we then evaluated the possible interaction of GPER and MR and EGFR. Our immunoprecipitation data indicated that aldosterone triggers a direct interaction between GPER and MR as well as GPER and EGFR (Figure 2E-2L). Immunofluorescence experiments performed in $\mathrm{SkBr} 3$ cells further corroborated the aforementioned results as an increased merged (orange) signal of MR and GPER was observed upon a short (15 $\mathrm{min})$ aldosterone treatment (Figure 2M-2O). Altogether, these data suggest that GPER may contribute to aldosterone/MR-activated EGFR signalling.

\section{GPER is involved in the aldosterone-mediated signalling}

On the basis of the abovementioned observations, we performed gene silencing experiments in order to assess whether GPER is involved in the rapid signalling induced by aldosterone. Interestingly, the activation of both EGFR and ERK1/2 by aldosterone was no longer evident silencing GPER in both $\mathrm{SkBr} 3$ cells and B-TEC (Figure 3A-3F). In accordance with these findings, the GPER antagonist G15 prevented the EGFR/ERK phosphorylation upon aldosterone exposure (Figure 3G3I). Next, the EGFR tyrosine kinase inhibitor AG1478 (AG) but not the MEK inhibitor PD98059 (PD) blocked EGFR phosphorylation by aldosterone (Figure 3G-3I), while ERK1/2 activation was prevented in the presence of both AG and PD. Hence, the MEK/ERK transduction pathway is activated afterward the engagement of EGFR upon aldosterone treatment in our model system. 
A

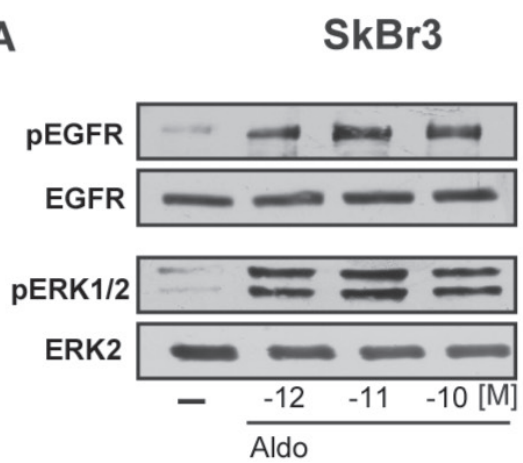

C
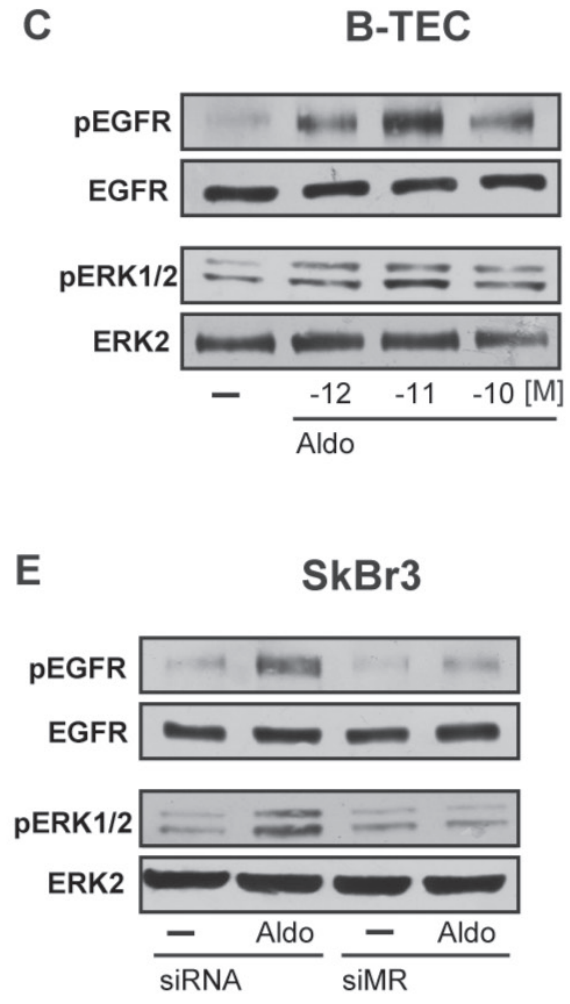

H

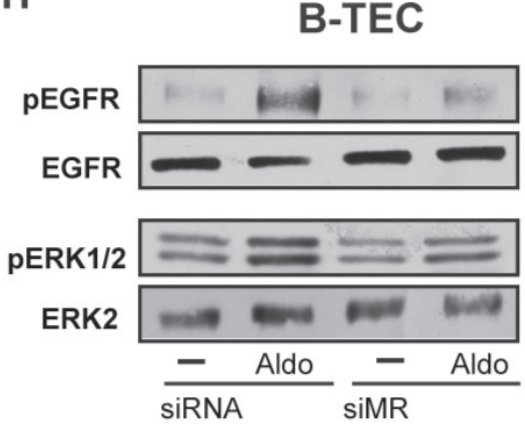

B $\square$ PEGFR

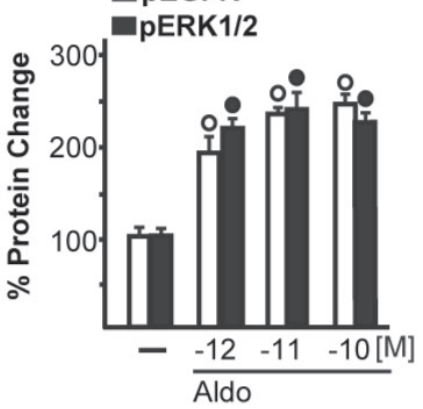

D

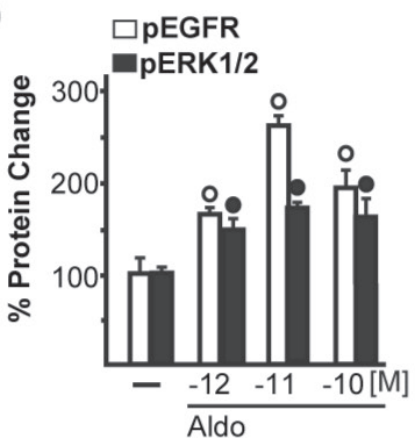

$\mathbf{F}$

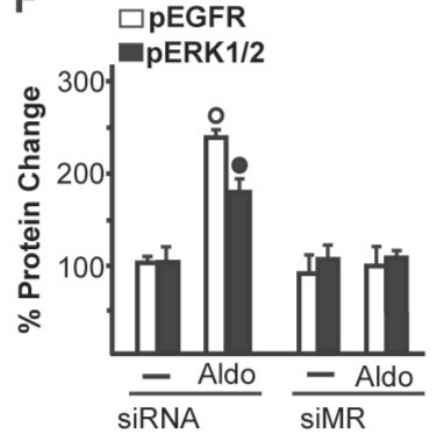

I

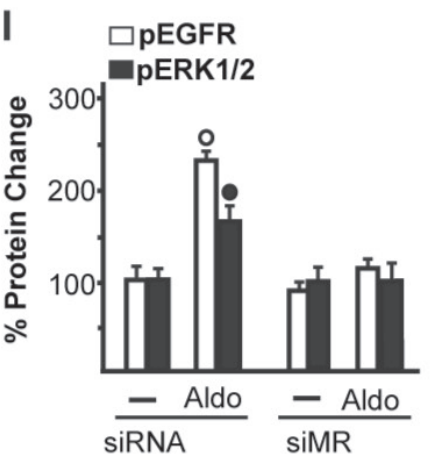

G SkBr3

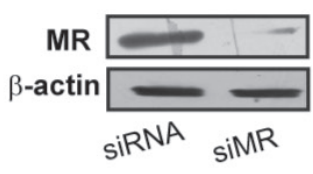

J B-TEC

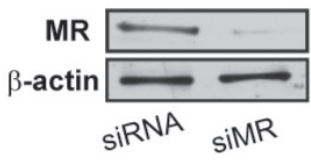

Figure 1: EGFR and ERK1/2 phosphorylation in SkBr3 cells. A., B. and B-TEC C., D. treated with Aldosterone (Aldo) for 15 min. EGFR and ERK1/2 phosphorylation in SkBr3 cells E., F. and B-TEC H., I. transfected for $24 \mathrm{~h}$ with siRNA or siMR and then treated with $10 \mathrm{pM}$ Aldo for $15 \mathrm{~min}$. G., J. Efficacy of MR silencing. The blots were normalized to EGFR or ERK2 and each data point represents the mean \pm SD of three independent experiments. ( () and $(\bullet)$ indicate $p<0.05$ for cells receiving vehicle (-) versus Aldo treatment. 

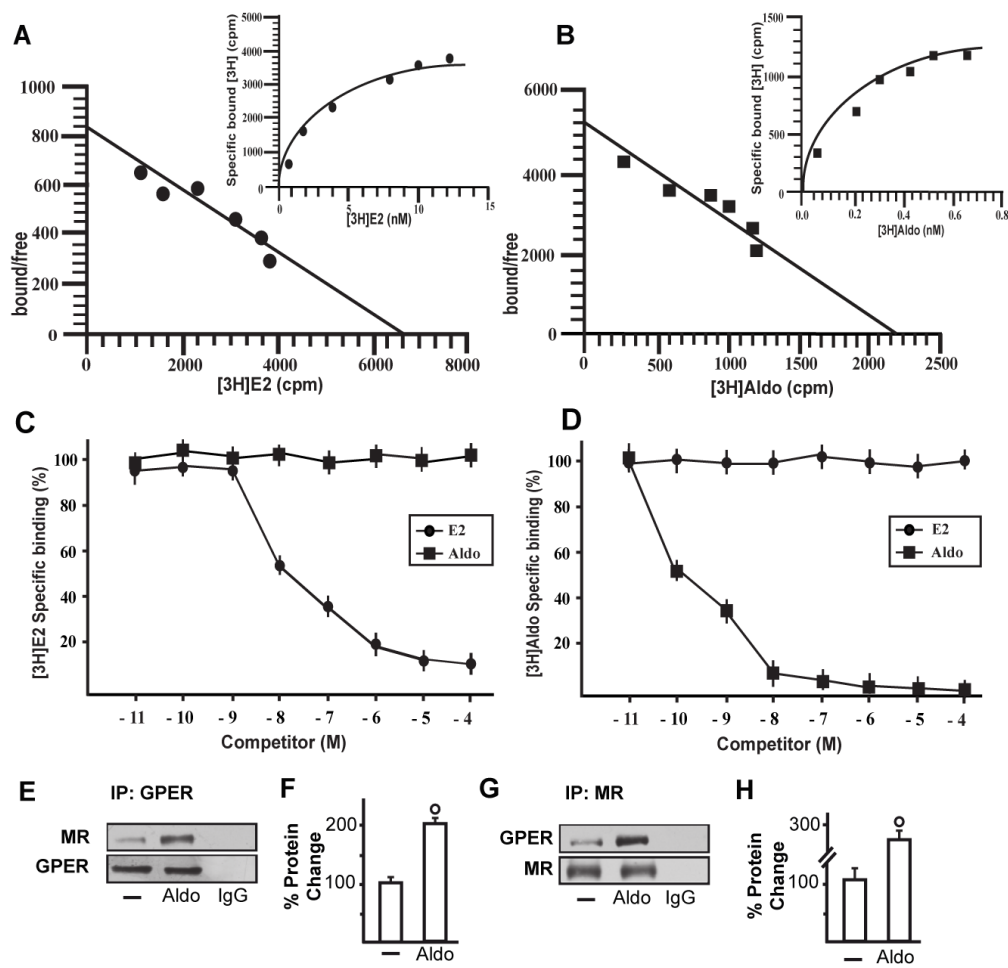

G IP: MR

H
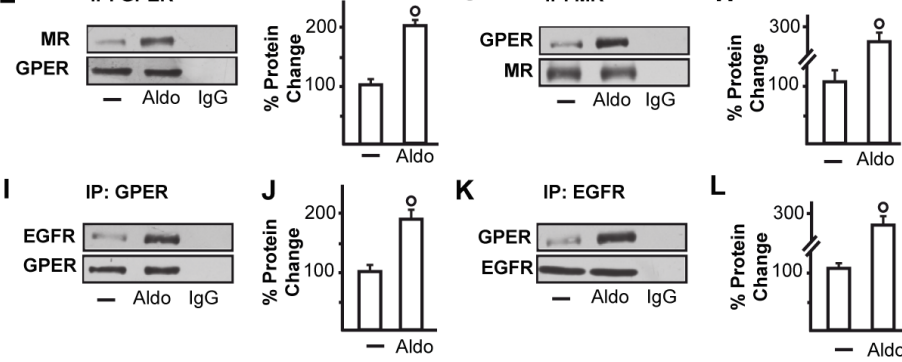

$\mathbf{L}$
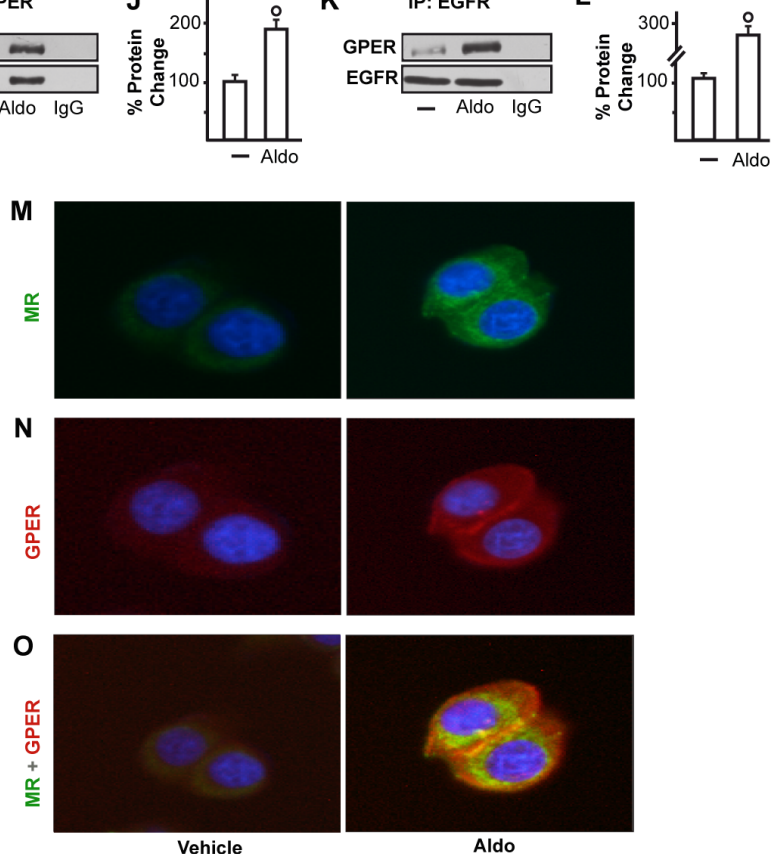

Figure 2: Representative saturation curve and Scatchard plot of $\left[{ }^{3} \mathrm{H}\right] 17 \beta$-estradiol (E2) binding. $\mathrm{A}$. and $\left[{ }^{3} \mathrm{H}\right]$ Aldosterone (Aldo) binding $\mathbf{B}$. in $\mathrm{SkBr} 3$ cells. Each value represents the mean \pm SEM of three determinations. Ligand binding assay in $\mathrm{SkBr} 3$ cells incubated with $\left.{ }^{3} \mathrm{H}\right] \mathrm{E} 2$ and exposed to increasing concentrations of E2 and Aldo for 2 hours $\mathbf{C}$.. Ligand binding assay in $\mathrm{SkBr} 3$ cells incubated with $\left[{ }^{3} \mathrm{H}\right]$ Aldo and exposed to increasing concentrations of E2 and Aldo for 2 hours D.. Competition curves are expressed as a percentage of maximum specific $\left[{ }^{3} \mathrm{H}\right] \mathrm{E} 2$ or $\left[{ }^{3} \mathrm{H}\right]$ Aldo binding. Each data point represents the mean \pm SEM of three independent experiments performed in triplicate. The co-immunoprecipitation of MR with GPER increases upon treatment with $10 \mathrm{pM}$ Aldo for 15 min in $\mathrm{SkBr} 3$ cells E.-H. The blots were normalized to GPER or MR, respectively. The interaction between GPER and EGFR increases upon treatment with $10 \mathrm{pM}$ Aldo for $15 \mathrm{~min}$ in $\mathrm{SkBr3}$ cells I.-L. The blots were normalized to GPER or EGFR, respectively. In control samples, nonspecific $\mathrm{IgG}$ was used instead of the primary antibody, as indicated. Each data point represents the mean $\pm \mathrm{SD}$ of three independent experiments. ( $\circ$ ) indicates $p<0.05$ for cells receiving vehicle (-) versus Aldo treatment. Localization of MR M. and GPER N. alone or in combination O., as evaluated by immunofluorescence in $\mathrm{SkBr} 3$ cells treated with $10 \mathrm{pM}$ Aldo for $15 \mathrm{~min}$. Green signal: MR; Red signal: GPER; Blue signal: Nuclei. Images shown are representative of ten random fields from three independent experiments. 


\section{SkBr3}

A

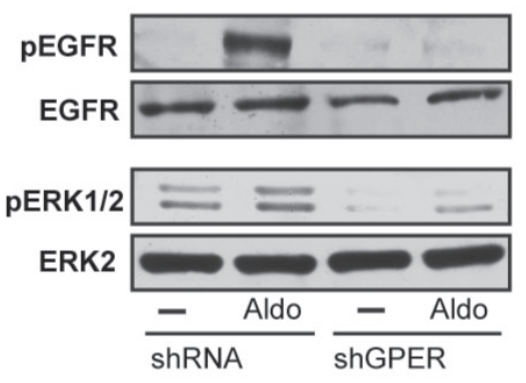

D

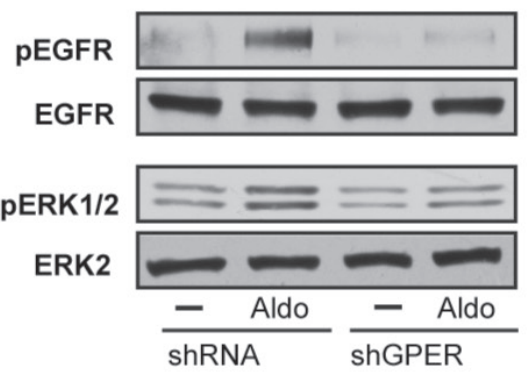

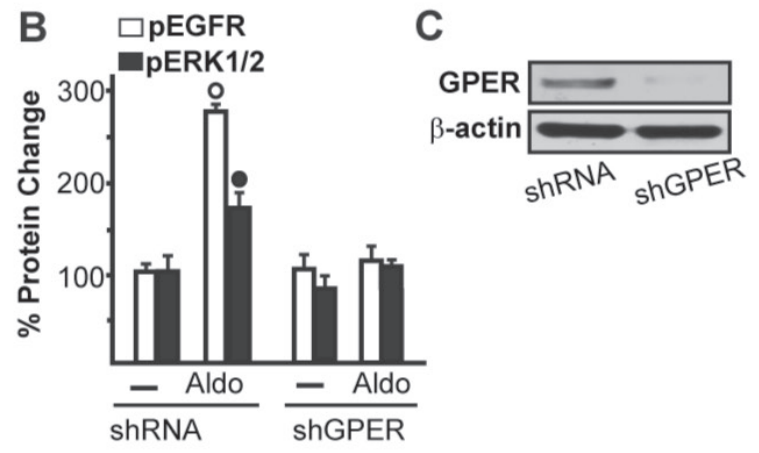

B-TEC

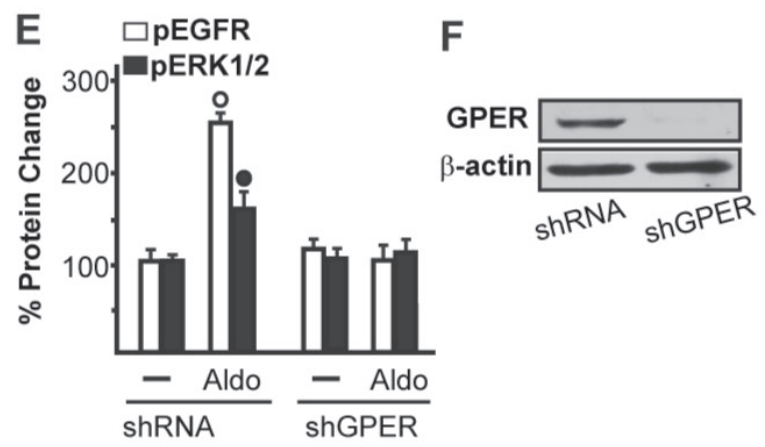

G

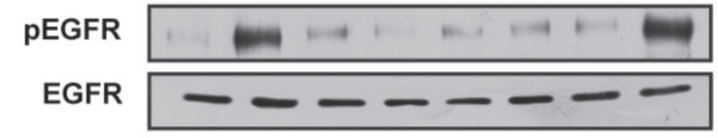

pERK1/2

ERK2

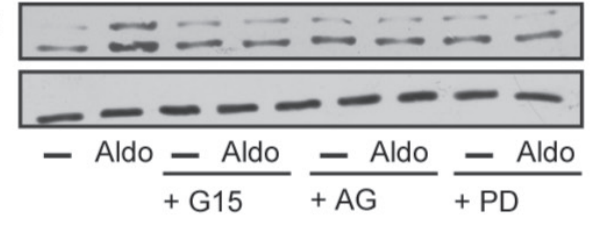

I

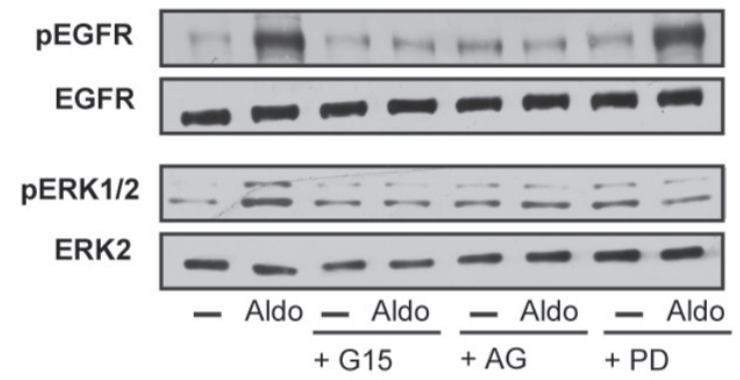

\section{H $\quad \square$ pEGFR}

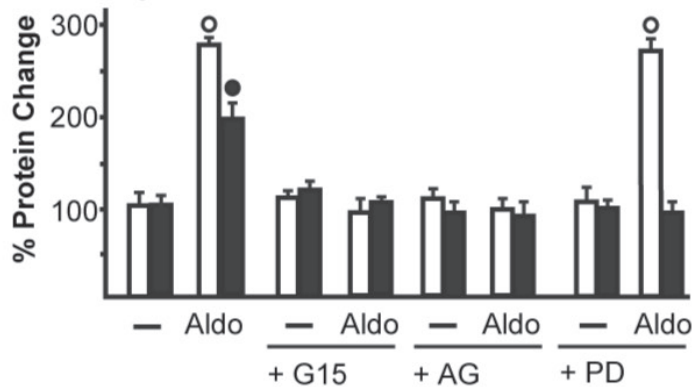

J

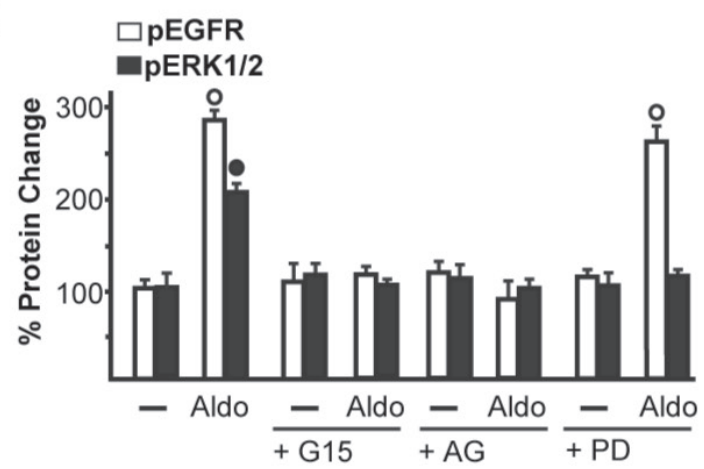

Figure 3: EGFR and ERK1/2 phosphorylation in SkBr3 cells. A., B. and B-TEC D., E. transfected for 24 h with shRNA or shGPER and then treated with $10 \mathrm{pM}$ Aldo for $15 \mathrm{~min}$. C., F. Efficacy of GPER silencing. EGFR and ERK1/2 activation in SkBr3 cells G., H. and B-TEC I., J. treated for 15 min with $10 \mathrm{pM}$ Aldo alone and in combination with $10 \mu \mathrm{M}$ EGFR inhibitor AG1478 (AG), $10 \mu \mathrm{M}$ MEK inhibitor PD98059 (PD) and 100 nM GPER antagonist G15. The blots were normalized to EGFR or ERK2 and each data point represents the mean \pm SD of three independent experiments. ( () and $(\bullet)$ indicate $p<0.05$ for cells receiving vehicle (-) versus Aldo treatment. 
Aldosterone/MR signalling stimulates the activity and expression of NHE-1, which has been involved in tumor cell migration, invasion and metastasis particularly in breast cancer [6-7, 45]. In this regard, we assessed that aldosterone prompts NHE-1 activity in both $\mathrm{SkBr} 3$ cells and B-TEC as evaluated by a fluorescent indicator of cytoplasmic $\mathrm{pH}$ changes (Figure 4A). In addition, aldosterone up-regulated NHE-1 at both the mRNA and protein levels as determined by real time PCR (Figure 4B) and immunofluorescence studies performed in $\mathrm{SkBr} 3$ cells and B-TEC (Figure 4C-4F). Next, the stimulatory effects induced by aldosterone on NHE-1 protein expression were abolished silencing MR (Figure 5) as well as GPER (Figure 6). Collectively, these findings suggest that NHE-1 regulation by aldosterone requires MR along with GPER.

\section{Aldosterone induces biological responses through both MR and GPER}

Functionally, we studied the role of MR and GPER in the proliferative effects of aldosterone in breast tumor cells as well as in the migration of tumor endothelial cells. Indeed, aldosterone triggered growth effects in $\mathrm{SkBr} 3$ cells, as assessed by cell counting (Figure 7A) and evidenced by time-lapse video microscopy (Videos 1-2). Cell proliferation stimulated by $10 \mathrm{pM}$ aldosterone was no longer evident silencing MR (Figure 7B-7C) or knockingdown GPER expression (Figure 7D-7E) and using the NHE-1 inhibitor cariporide (Figure 7F). Similar results were obtained using aldosterone concentrations up to 10 $\mathrm{nM}$ (data not shown). Furthermore, aldosterone promoted the migration of B-TEC as evidenced by time-lapse video microscopy (Videos 3-4) and scratch assay (Figure 8). The observed aldosterone-induced motility was abrogated silencing MR (Figure 8A, 8B, 8F) or GPER (Figure $8 \mathrm{C}-8 \mathrm{D}, 8 \mathrm{G}$ ) and in the presence of cariporide (Figure $8 \mathrm{E})$. Overall, these results indicate that the functional interaction between MR and GPER is involved in the aforementioned stimulatory action of aldosterone in both $\mathrm{SkBr} 3$ cells and B-TEC.

\section{DISCUSSION}

In the present study we provide novel evidence regarding the molecular mechanisms by which GPER may contribute to the biological responses induced by aldosterone in breast cancer cells and breast tumor-derived endothelial cells. In particular, we have demonstrated that aldosterone activates the EGFR/ERK transduction signalling through the classic MR and the involvement of GPER, as evidenced by gene silencing experiments and pharmacological inhibitors. In addition, we have shown that both MR and GPER mediate the aldosteroneinduced up-regulation of $\mathrm{Na}^{+} / \mathrm{H}^{+}$exchanger-1 (NHE-1), a well-known MR target involved in cancer progression
$[7,45]$. We have also evidenced that aldosterone does not bind to GPER in accordance with previous studies [44], however it triggers the direct interaction between MR and GPER as well as GPER and EGFR. Interestingly, we have determined that both MR and GPER are required for the proliferation and migration of breast cancer cells and B-TEC mediated by NHE-1 upon aldosterone exposure.

Aldosterone elicits important biological effects in several physio-pathological conditions, spanning from electrolyte and fluid homeostasis to the regulation of fibrotic, inflammatory, proliferative and angiogenic responses in cardiovascular, metabolic diseases and cancer [12-13, 46-49]. As it concerns the breast tissue, it has been demonstrated that aldosterone potentiates prolactin stimulation of casein synthesis in pregnant rabbit mammary gland and contributes to mammary gland development and differentiation [50].

The actions exerted by aldosterone mainly occur through the binding to MR, a ligand-inducible transcription factor that belongs to the nuclear receptor superfamily [1]. The enzyme 11 $\beta$-hydroxysteroid dehydrogenase type II (11ßHSD2), which catalyzes the conversion of $11 \beta$-hydroxycorticosteroids like cortisol and corticosterone to the respective 11-keto metabolites namely cortisone and 11-dehydrocorticosterone, does allow the aldosterone binding to MR [51]. 11ßHSD2 is mainly expressed in mineralcorticoid target tissues like kidney, colon, salivary glands and placenta [51]. In addition, immunohistochemical studies have detected in normal and malignant breast tissues high levels of $11 \beta-H S D 2$ that co-localize with MR [52]. Previous studies have also evaluated the 11ß-HSD2 activity in breast cancer cells, suggesting that this enzyme may play a regulatory role of aldosterone action in breast malignancy [53]. According to the classical model of MR signalling, the interaction between aldosterone and un-liganded receptor promotes the dissociation of the heat shock proteins from MR, which translocates into the nucleus [1]. Then, the aldosterone/MR complex binds to specific response elements located within the regulatory region of target genes, hence resulting in gene expression changes [1]. In addition, aldosterone induces rapid effects through alternate mechanisms including the activation of the EGFR/ERK transduction pathway, as demonstrated in different animal and cell models [3-4]. The existence of aldosterone receptors structurally unrelated to the classic MR paved also the way for analyzing the role of further mediators of the multifaceted action elicited by aldosterone [49].

GPER has been largely demonstrated to mediate estrogenic signalling in a wide number of physiopathological conditions, including cancer [54-64]. GPER has been also involved in functional responses to aldosterone in various experimental contexts [3740]. For instance, the ability of aldosterone in activating ERK1/2 in vascular smooth muscle cells and sensitizing 
A

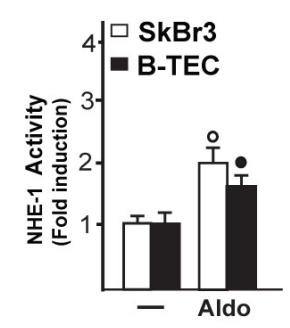

B

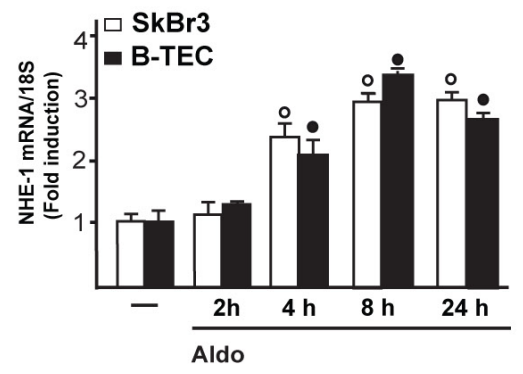

C
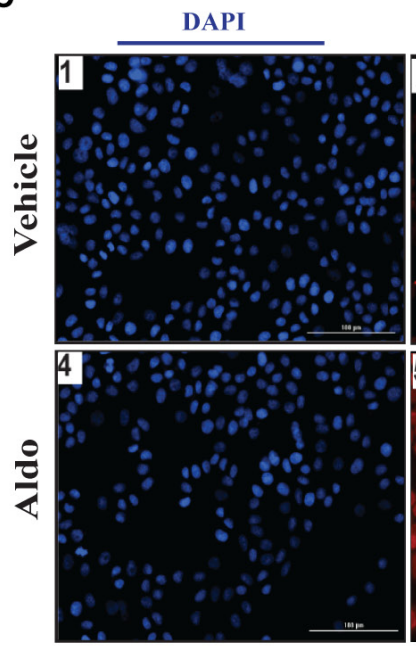

E

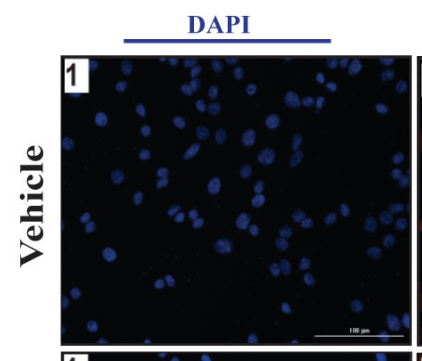

B-TEC
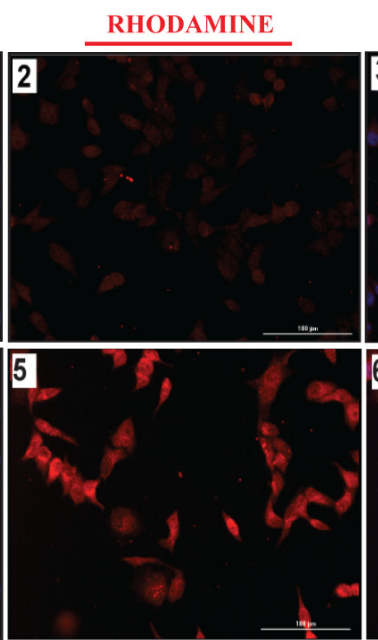

SkBr3
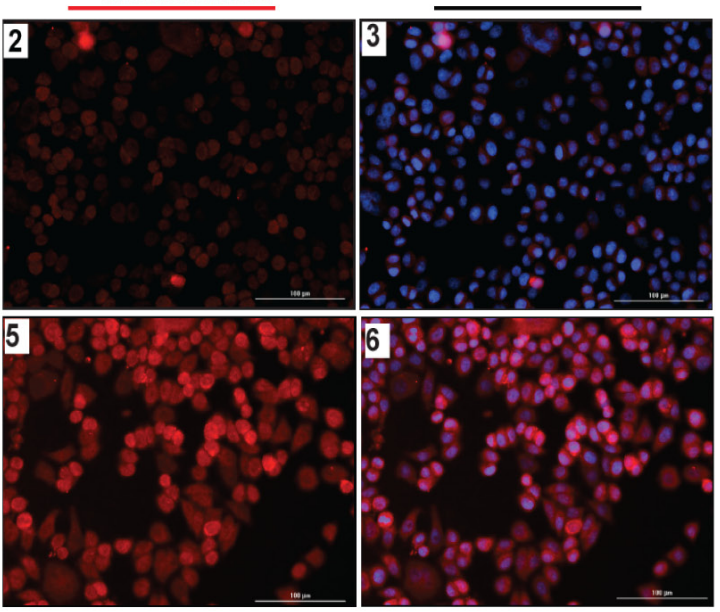

D

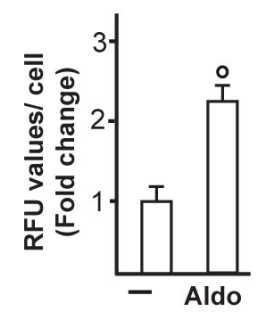

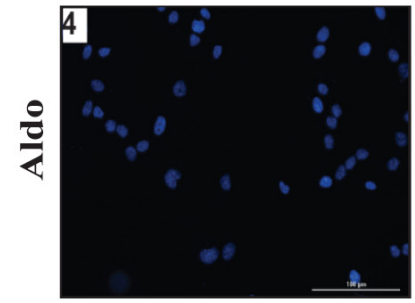

$\mathbf{F}$
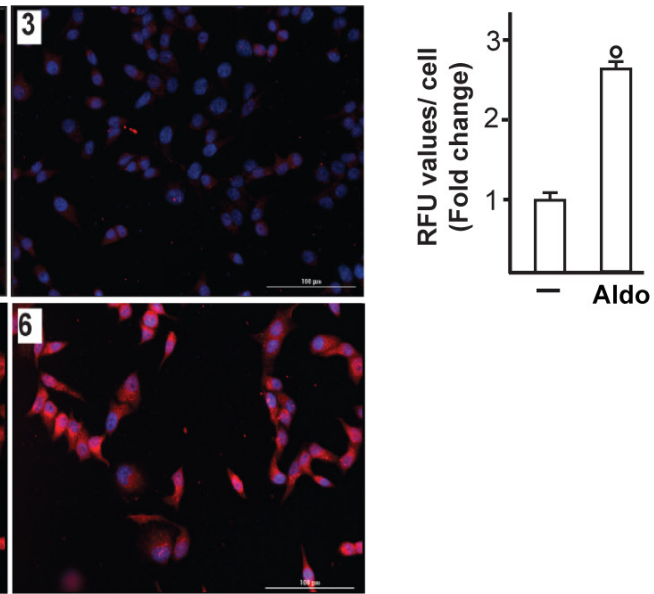

Figure 4: $\mathrm{Na}^{+} / \mathrm{H}^{+}$Exchanger 1 (NHE-1) activity in $\mathrm{SkBr3}$ cells and B-TEC treated with $10 \mathrm{pM}$ Aldo, as evaluated by fluorescence intensity measurement. $\mathbf{A}$. Each data point represents the mean $\pm \mathrm{SD}$ of three independent experiments. mRNA expression of NHE-1 in SkBr3 cells and B-TEC treated with $10 \mathrm{pM}$ Aldo, as evaluated by real-time PCR B.. Values are normalized to the $18 \mathrm{~S}$ expression and shown as fold changes of the mRNA expression induced by Aldo respect to cells treated with vehicle (-). NHE-1 expression as evaluated by immunofluorescence in SkBr3 cells $\mathbf{C}$. and B-TEC E. treated with ethanol as vehicle or $10 \mathrm{pM}$ Aldo for 8 hours. NHE-1 accumulation is shown by the red signal, nuclei were stained by DAPI (blue signal). Images shown are representative of three independent experiments. D., F. Fluorescence intensities for the red channel were quantified in 10 random fields for each condition and results are expressed as fold change of relative fluorescence units (RFU) over the vehicle-treated cells. (०) and (•) indicate $p<0.05$ for cells receiving vehicle (-) versus Aldo treatment. 
SkBr3

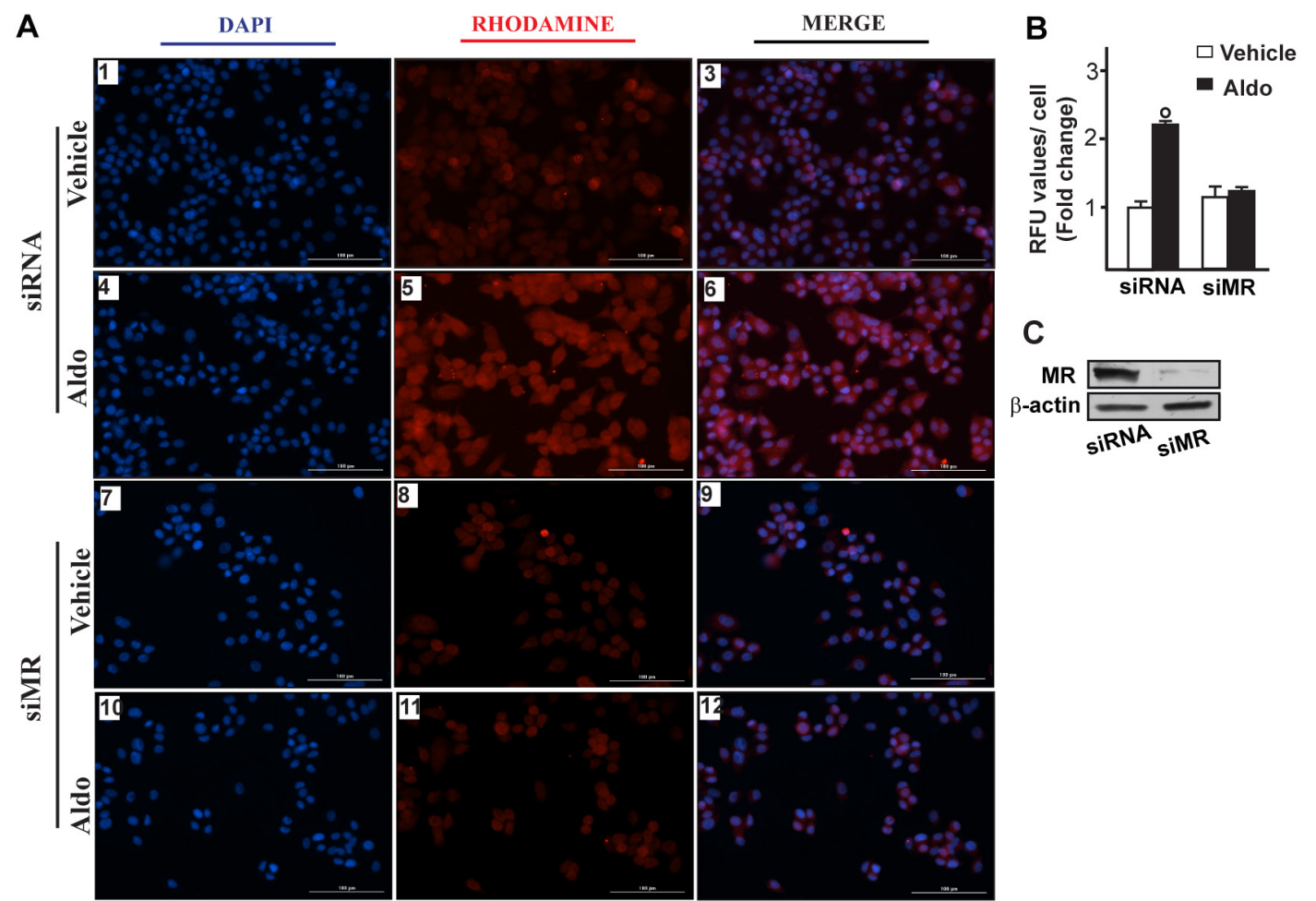

B-TEC

D

DAPI RHODAMINE

MERGE
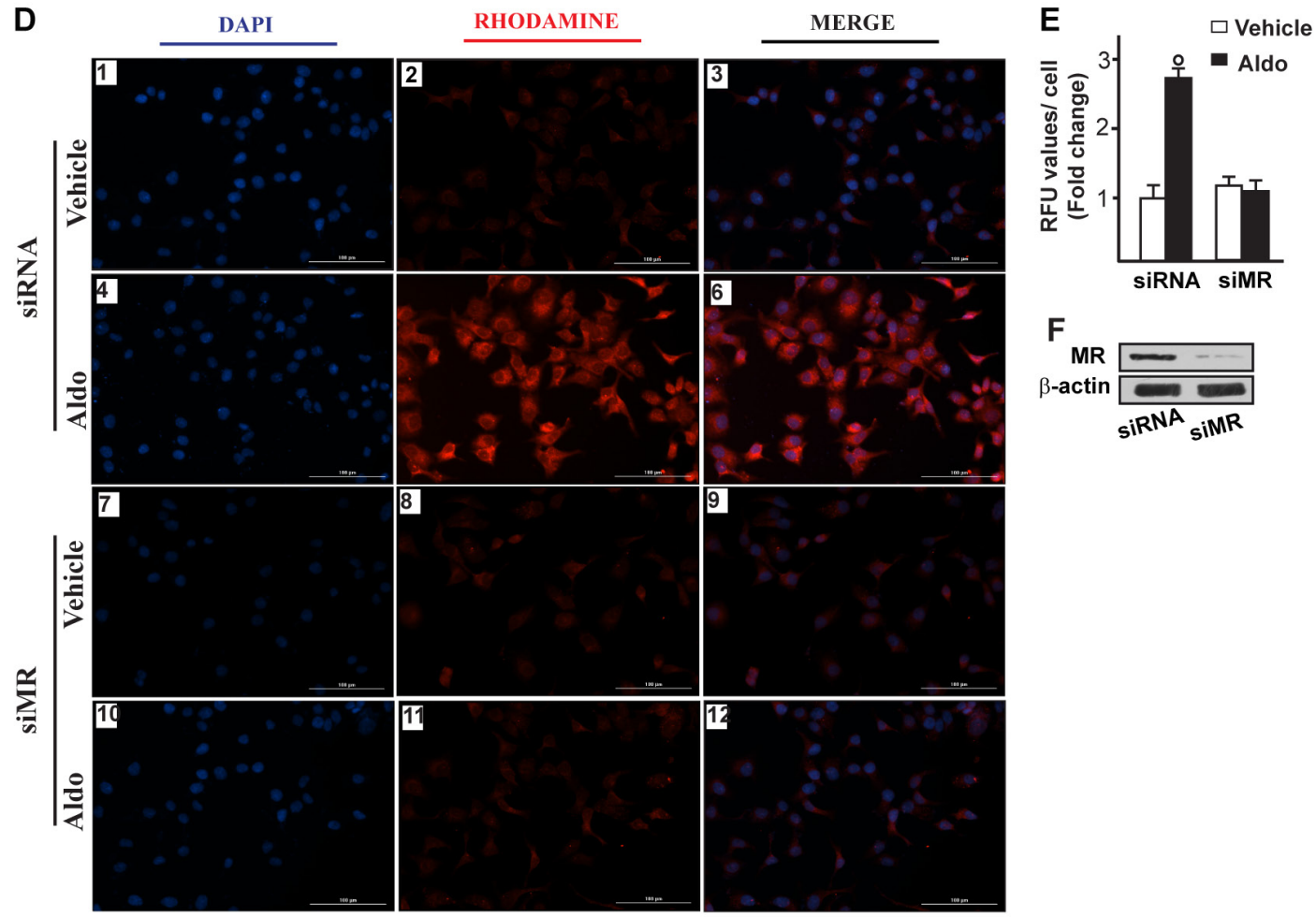

$\mathbf{F}$

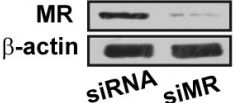

Figure 5: $\mathrm{Na}^{+} / \mathrm{H}^{+}$Exchanger 1 (NHE-1) expression as evaluated by immunofluorescence in SkBr3 cells. A. and B-TEC D. transfected for 24 hours with siRNA (panels 1-6) or siMR (panels 7-12) and then treated with ethanol as vehicle or $10 \mathrm{pM} \mathrm{Aldosterone} \mathrm{(Aldo)}$ for 8 hours. NHE-1 accumulation is shown by the red signal, nuclei were stained by DAPI (blue signal). Images shown are representative of three independent experiments. B., E. Fluorescence intensities for the red channel were quantified in 10 random fields for each condition and results are expressed as fold change of relative fluorescence units (RFU) over the vehicle-treated cells. C., F. Efficacy of MR silencing. (०) indicates $p<0.05$ for cells receiving vehicle versus Aldo treatment. 
SkBr3

A

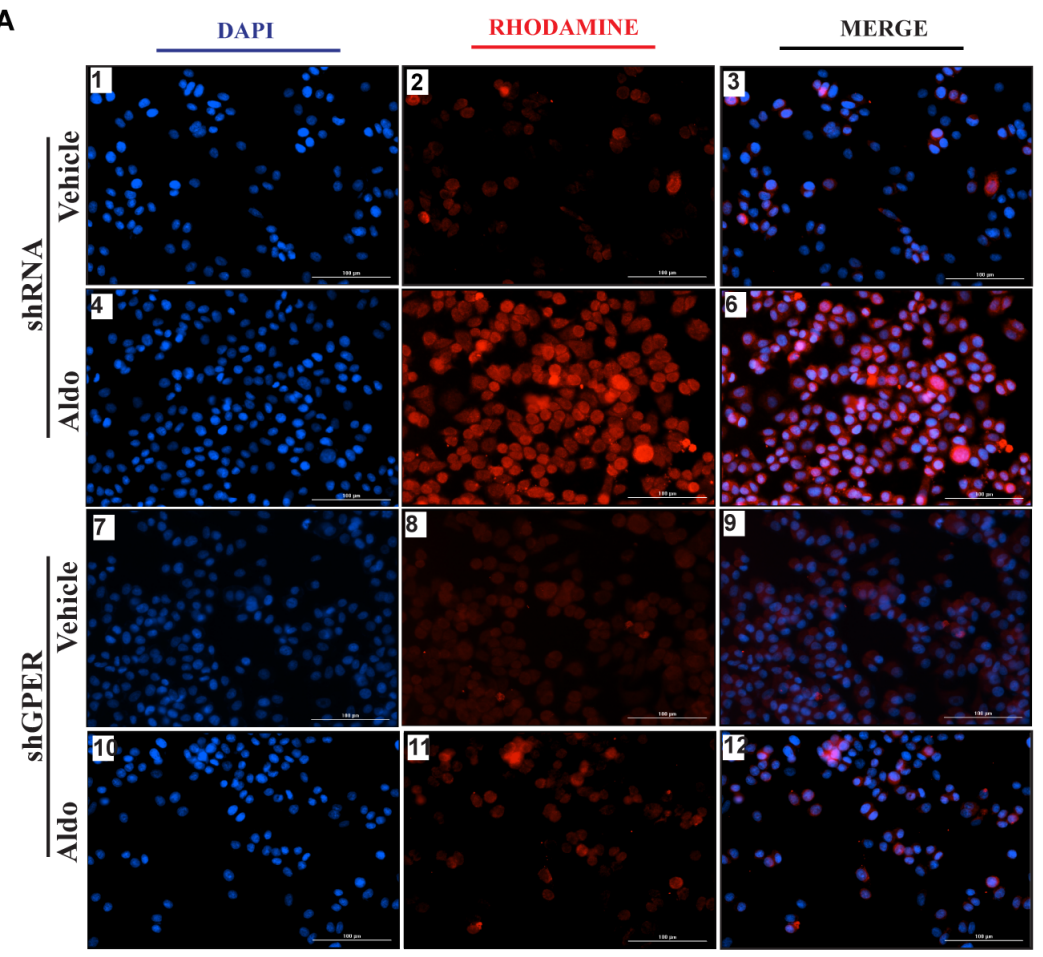

B-TEC

D

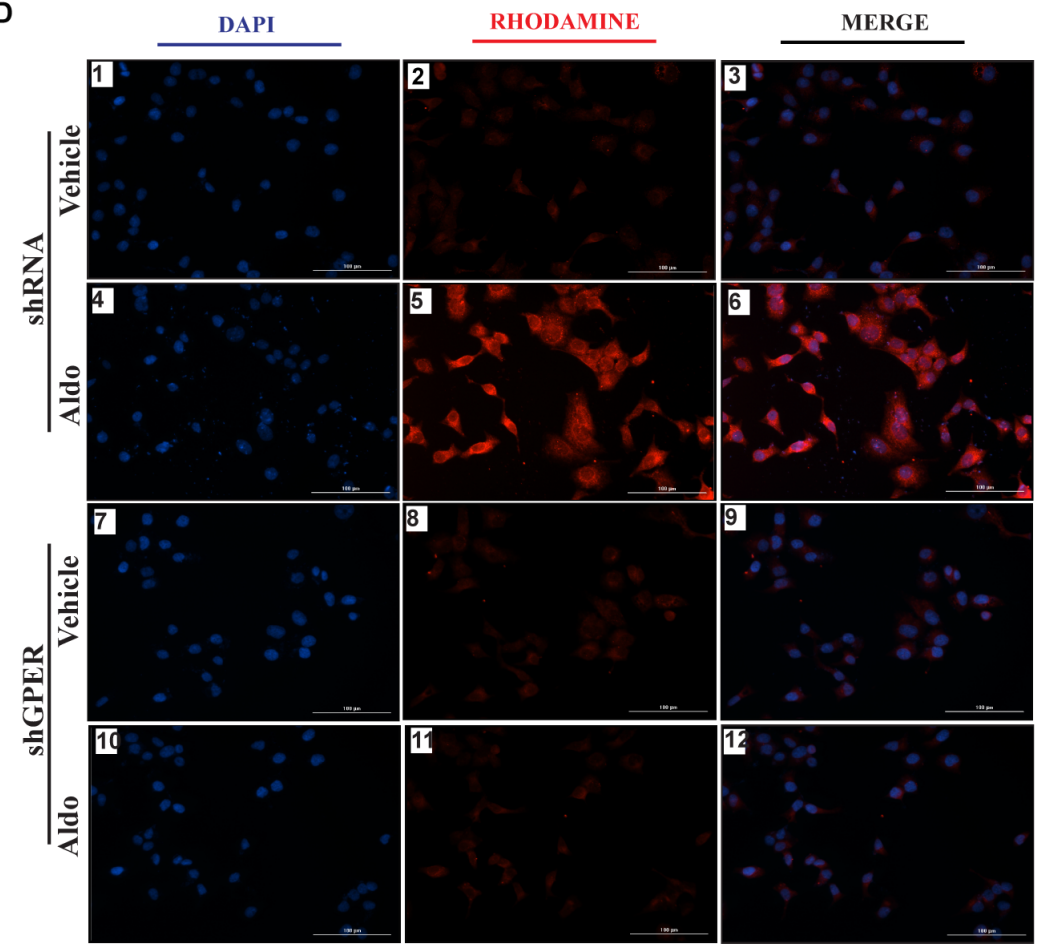

B

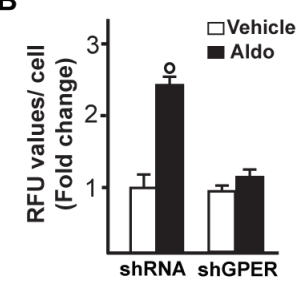

C

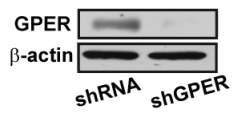

E

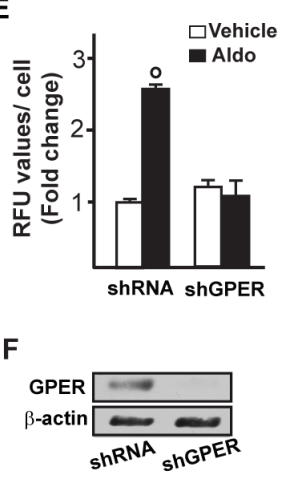

Figure 6: $\mathrm{Na}^{+} / \mathrm{H}^{+}$Exchanger 1 (NHE-1) expression as evaluated by immunofluorescence in SkBr3 cells. A. and B-TEC D. transfected for 24 hours with shRNA (panels 1-6) or shGPER (panels 7-12) and then treated with ethanol as vehicle or $10 \mathrm{pM}$ aldosterone (Aldo) for 8 hours. NHE-1 accumulation is shown by the red signal, nuclei were stained by DAPI (blue signal). Images shown are representative of three independent experiments. B., E. Fluorescence intensities for the red channel were quantified in 10 random fields for each condition and results are expressed as fold change of relative fluorescence units (RFU) over the vehicle-treated cells. C., F. Efficacy of GPER silencing. ( $($ ) indicates $p<0.05$ for cells receiving vehicle (-) versus Aldo treatment. 
the connecting tubule glomerular feedback in afferent arterioles was prevented using both MR and GPER blockers [38-40]. Other studies evidenced that the increase of cardiac vagal tone observed upon aldosterone treatment is abolished in the presence of the GPER antagonist G36 but not using the MR antagonists spironolactone and eplerenone [39]. In rat aortic endothelial cells devoid of MR, the biological effects triggered by aldosterone were mimicked by the GPER agonist G-1 and prevented using pharmacological inhibitors of GPER as well as knocking down its expression [38]. The aforementioned observations suggest that GPER is involved in the effects exerted by aldosterone either through MR or acting as an alternate aldosterone receptor. However, it should be pointed out that diverse controversies argue against the last conclusion, as pharmacologic criteria for GPER to be considered as an aldosterone-responsive receptor are not still adequately fulfilled [41-43]. Indeed, binding studies performed in HEK cells overexpressing GPER (HEKGPER-1) showed that aldosterone and the MR antagonists, spironolactone and eplerenone, do not compete for specific $\left[{ }^{3} \mathrm{H}\right] \mathrm{E} 2$ binding to membrane of HEK-GPER-1 cells [44].

\section{SkBr3}
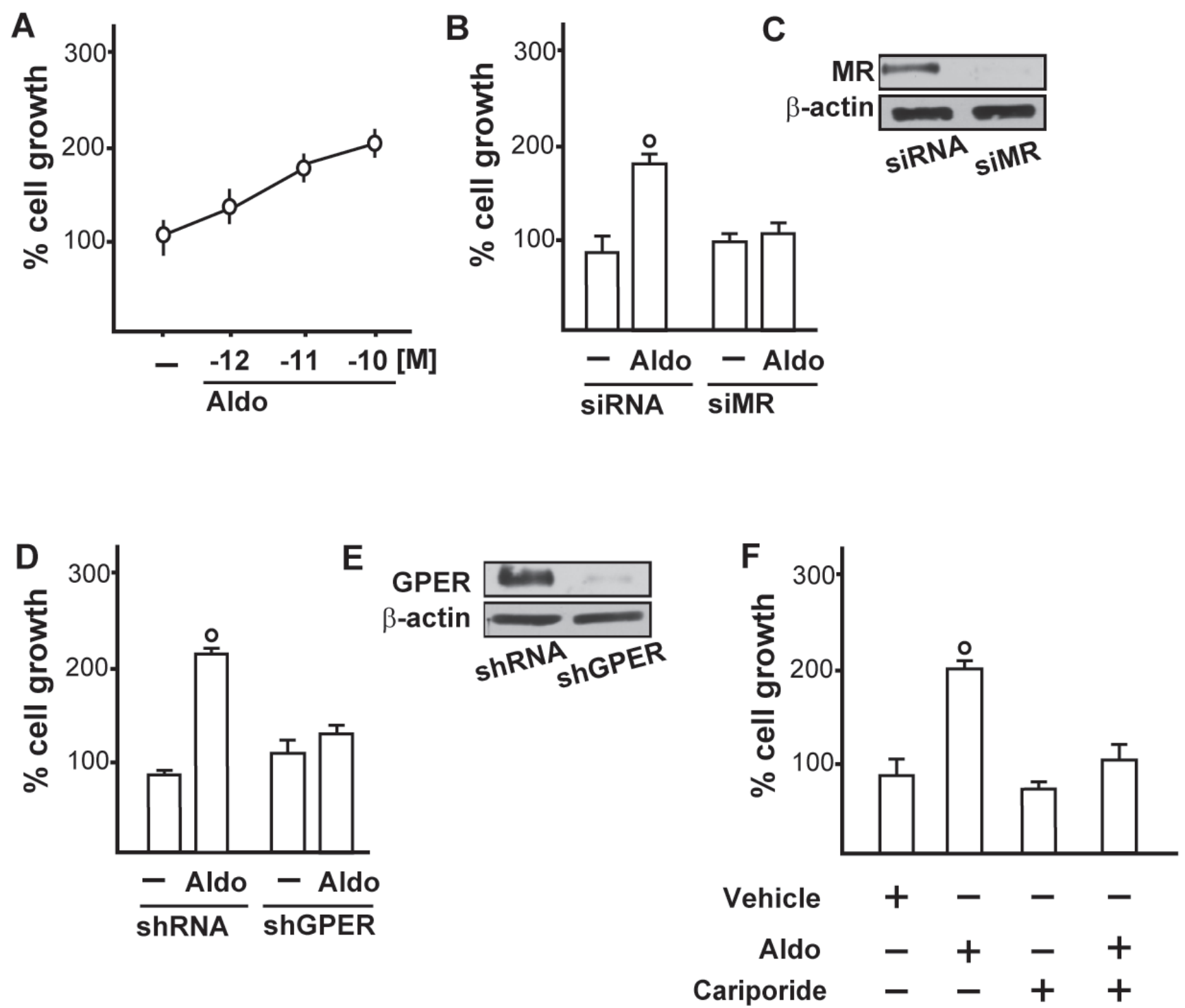

Figure 7: A. $\mathrm{SkBr} 3$ cell proliferation upon treatment for 5 days with increasing concentrations of Aldosterone (Aldo). Proliferation of $\mathrm{SkBr} 3$ cells transfected with siMR B., C. and shGPER D., E. and treated for 5 days with $10 \mathrm{pM}$ Aldo. SkBr3 cell proliferation stimulated by $10 \mathrm{pM}$ Aldo in the presence of $50 \mu \mathrm{M} \mathrm{Na}^{+} / \mathrm{H}^{+}$Exchanger 1 (NHE-1) inhibitor named cariporide $\mathbf{F}$. Values shown are mean $\pm \mathrm{SD}$ of three independent experiments performed in triplicate. ( $($ ) indicates $p<0.05$ for cells receiving vehicle (-) versus Aldo treatment. 
In accordance with these findings, in the present study aldosterone failed to bind to GPER in competition assays based on experimental approaches used in previous investigations in order to characterize the binding properties of GPER ligands [28, 31-32, 34-36]. Worthy, we found that aldosterone stimulates the interaction of GPER with MR and EGFR, thus suggesting a further mechanism through which ligand-activated MR triggers EGFR signalling [49, 65-67]. Nicely supporting the functional cross-talk between MR and GPER, we ascertained that both receptors are required for the aldosterone-induced expression of NHE-1 which is considered as a molecular sensor of MR activation [45]. In this respect, our data are reminiscing of previous findings showing that EGFR and GPER cooperate toward the regulation of NHE-1 function upon aldosterone treatment [40, 66]. Importantly, we found that the stimulatory effects elicited by aldosterone on the proliferation and migration of breast cancer cells and breast tumor-derived endothelial cells are mediated by NHE-1 and involve both GPER and MR. Hence, the current results further extend the well-known action played by NHE-1 toward negative biological features, in particular in breast cancer $[7,68]$. In this regard, it is worth mentioning that in tumor metabolic microenvironment

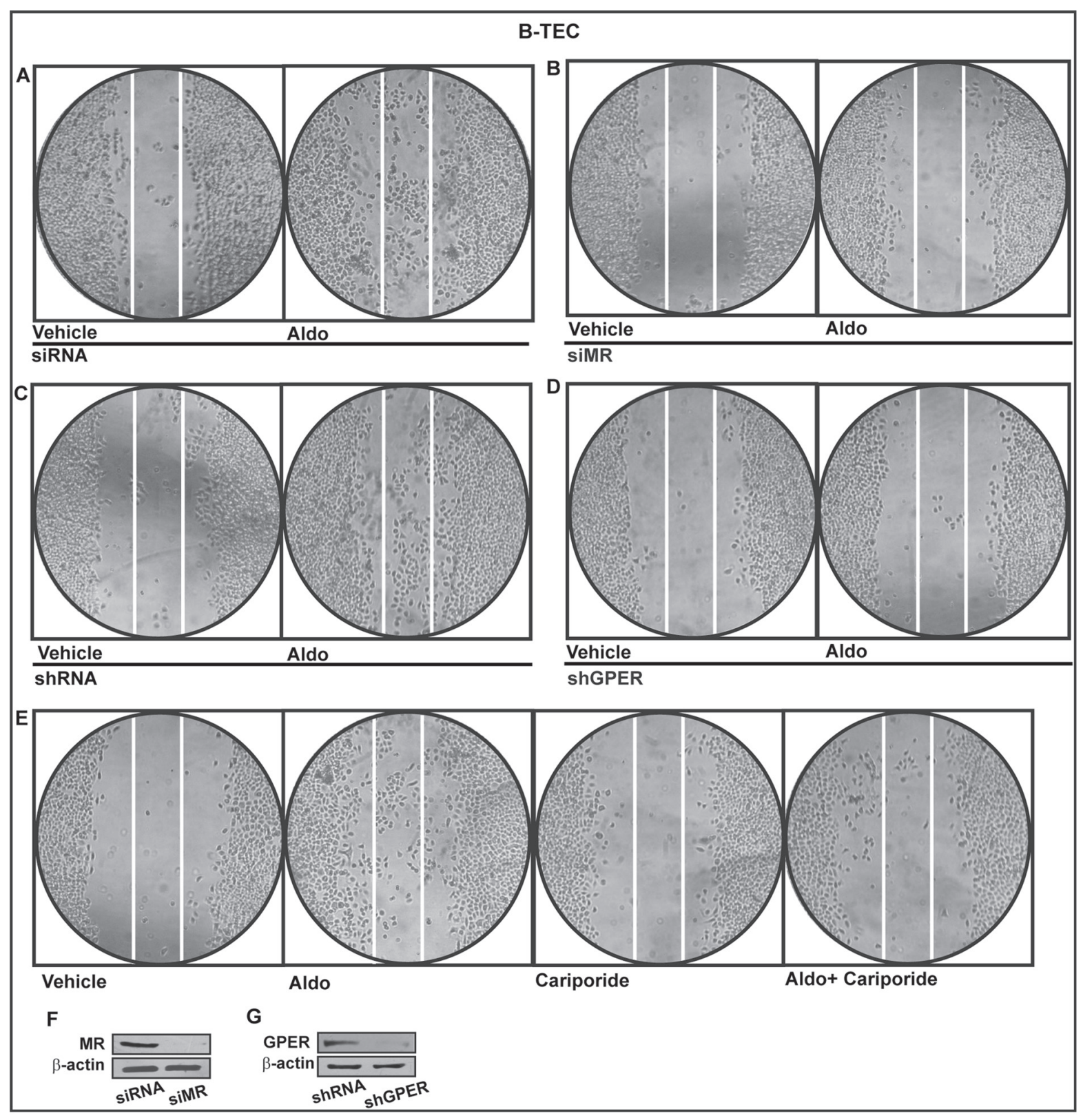

Figure 8: Cell migration in B-TEC transfected for $\mathbf{2 4} \mathbf{h}$ with siRNA. A., siMR B., shRNA C. or shGPER D. and then treated for 48 hours with ethanol as vehicle or $10 \mathrm{pM}$ Aldosterone (Aldo). E. Cell migration stimulated by $10 \mathrm{pM}$ Aldo in B-TEC in the presence of $50 \mu \mathrm{M} \mathrm{Na}+/ \mathrm{H}+$ Exchanger 1 (NHE-1) inhibitor cariporide. F., G. Efficacy of MR and GPER silencing. Data are representative of three independent experiments performed in triplicate. 
characterized by hypoxic-acidic milieu [69], the dysregulation of $\mathrm{pH}$ homeostasis mediated by NHE-1 may actually contribute to key steps in tumor progression like increased cell proliferation, loss of cell-cell contact and detachment from the extracellular matrix [68]. In breast cancer cells and breast cancer associated fibroblasts exposed to hypoxia, we have previously assessed that GPER cooperates with hypoxia inducible factor-1 (HIF1) toward the regulation of vascular endothelial growth factor (VEGF) and tumor angiogenesis [70-73]. Hence, the present findings suggest further mechanisms through which GPER may play a role in the complex adaptive responses to hypoxic-acidic tumor microenvironment. Additionally, our results indicate that GPER contributes to the effects mediated by aldosterone/MR signalling, as evidenced by other ligand-activated steroid receptors [74$75]$.

Collectively, our findings provide novel insights into the controversial mechanisms through which GPER contributes to aldosterone-mediated signalling. On the basis of our data showing that the functional interaction between MR and GPER triggers certain stimulatory effects exerted by aldosterone, GPER may be considered as a further target within the intricate transduction network activated by aldosterone in particular in breast cancer.

\section{MATERIALS AND METHODS}

\section{Reagents}

Aldosterone (Aldo), 17 $\beta$-estradiol (E2) and Cariporide were purchased from Sigma Aldrich (Milan, Italy). G15 ((3aS,4R,9bR)-4-(6-bromo-1,3-benzodioxol5-yl)-3a,4,5,9b-3H-cyclopenta[c]quinolone) was obtained from Tocris Bioscience (distributed by Space, Milan, Italy). Tyrphostin AG1478 (AG) was purchased from DBA (Milan, Itay). PD98059 (PD) was obtained from Calbiochem (DBA, Milan, Italy). All compounds were dissolved in dimethyl sulfoxide (DMSO) except Aldosterone and E2 which were solubilized in ethanol.

\section{Cell cultures}

$\mathrm{SkBr} 3$ breast cancer cells were maintained in RPMI-1640 without phenol red, supplemented with $10 \%$ fetal bovine serum (FBS) and $100 \mu \mathrm{g} / \mathrm{ml}$ penicillin/ streptomycin (Life Technologies, Milan, Italy). Breast tumor-derived endothelial cells (B-TEC) were obtained from human breast carcinomas and characterized as previously described [76]. B-TEC showed constant expression of endothelial markers and increased angiogenic properties, migration and drug resistance in respect to normal microendothelial cells [76-78]. Briefly, specimens were finely minced with scissors and then digested by incubation for $1 \mathrm{~h}$ at $37^{\circ} \mathrm{C}$ in DMEM containing collagenase IV (Sigma Aldrich, Milan, Italy). After washings in medium plus $10 \%$ FCS (Life Technologies, Milan, Italy), the cell suspension was forced through a graded series of meshes to separate the cell components from stroma and aggregates. Endothelial cells were isolated from cells suspension using antiCD105 Ab coupled to magnetic beads, by magnetic cell-sorting using the MACS system (Miltenyi Biotech, Auburn, CA). B-TEC were seeded on collagen-coated flasks (Sigma-Aldrich Srl, Milan, Italy) and cultured in Endothelial Growth Medium (EGM) (Lonza, Milan, Italy), supplemented with 5\% FBS (Lonza, Milan, Italy). MCF-7 breast cancer cells were maintained in DMEM F12 supplemented with $10 \%$ FBS and $100 \mu \mathrm{g} / \mathrm{mL}$ penicillin/streptomycin (Life Technologies, Milan, Italy). All cell lines were grown in a $37^{\circ} \mathrm{C}$ HeraCell incubator (ThermoScientific-Heraeus, Milan, Italy) with $5 \% \mathrm{CO}_{2}$. Cells were switched to medium without serum the day before experiments.

\section{Saturation curve and scatchard plot analysis}

$\mathrm{SkBr} 3$ cells were grown in $10-\mathrm{cm}$ cell culture dishes and incubated with increasing concentrations of $[2,4,6$, 7-3H] E2 (89 Ci/mmol; GE Healthcare) or [1, 2, 6, 7-3H] Aldosterone ( $85 \mathrm{Ci} / \mathrm{mmol}$; Perkinelmer). Cells were then washed with ice-cold phosphate-buffered saline (PBS); after $100 \%$ ethanol extraction of cells, radioactivity was measured by liquid scintillation counting. The plot of the bound radioactivity (cpm) versus the concentration of the radiotracer (nM) was fitted to the saturation binding curve using Prism GraphPad program (GraphPad Software, San Diego, CA), which was used to calculate the binding dissociation constant (Kd) and binding capacity (Bmax).

\section{Ligand binding assay}

$\mathrm{SkBr} 3$ cells were grown in $10-\mathrm{cm}$ cell culture dishes and incubated with $4 \mathrm{nM}[2,4,6,7-3 \mathrm{H}] \mathrm{E} 2$ (89 $\mathrm{Ci} / \mathrm{mmol}$; GE Healthcare) or $100 \mathrm{pM}$ [1, 2, 6, 7-3H] Aldosterone ( $85 \mathrm{Ci} / \mathrm{mmol}$; Perkinelmer) in the presence or absence of increasing concentrations of nonlabeled E2 or aldosterone for 2 hours at $37^{\circ} \mathrm{C}$. Cells were then washed with ice-cold PBS; after $100 \%$ ethanol extraction of cells, radioactivity was measured by liquid scintillation counting. The displacement of $\left[{ }^{3} \mathrm{H}\right] \mathrm{E} 2$ or $\left[{ }^{3} \mathrm{H}\right]$ Aldo binding by the competitors was expressed as a percentage of the maximum specific binding of E2 or Aldo.

\section{$\mathrm{Na}^{+} / \mathrm{H}^{+}$Exchanger 1 (NHE-1) activity assay}

$\mathrm{SkBr} 3$ cells and B-TEC were grown in $10-\mathrm{cm}$ cell culture dishes and then shifted for $24 \mathrm{~h}$ to medium 
lacking serum. Then, $4 \times 10^{7}$ cells $/ \mathrm{ml}$ were suspended in HEPES buffer solution 1M (Sigma Aldrich, Milan, Italy) and incubated with a membrane-permeable fluorescent indicator for the measurement of cytoplasmic $\mathrm{pH}$ namely SPIRO(ISOBENZOFURAN-1(3H),9'-(9H) XANTHENE)-2',7'-DIPROPANOIC ACID (BCECFAM) $(0,3 \mu \mathrm{M})$ (Santa Cruz Biotechnology, Milan, Italy) for $30 \mathrm{~min}$ at $37^{\circ} \mathrm{C}$. Then, cells were washed with HEPES buffer saline and a cell suspension of $3 \times 10^{6}$ cells $/ \mathrm{ml}$ was prepared. Fluorescence ratio from the dye was measured using an FLX-800 micro plate fluorimeter (Bio-Tek Instruments, Inc., Winooski, VT, USA).

\section{Gene expression studies}

Total RNA was extracted from cell cultures using the TRIzol commercial kit (Life Technologies, Milan, Italy) according to the manufacturer's protocol. RNA was quantified spectrophotometrically and quality was checked by electrophoresis through agarose gels stained with ethidium bromide. Only samples that were not degraded and showed clear $18 \mathrm{~S}$ and $28 \mathrm{~S}$ bands under UV light were used for RT-PCR. Total cDNA was synthesized from the RNA by reverse transcription using the murine leukemia virus reverse transcriptase (Life Technologies, Milan, Italy), following the protocol provided by the manufacturer. The expression of selected genes was quantified by real-time PCR using Step One (TM) sequence detection system (Applied Biosystems Inc, Milan, Italy), following the manufacturer's instructions. Gene-specific primers were designed using Primer Express version 2.0 software (Applied Biosystems. Inc., Milan, Italy) and are as follows: GPER Fwd: 5'-ACACACCTGGGTGGACACAA-3' and Rev: 5'-GGAGCCAGAAGCCACATCTG-3'; MR Fwd: 5'-GCTTTGATGGTAACTGTGAAGG-3' and Rev: 5'- TGTGTTGCCCTTCCACTGCT-3'; ER $\alpha$ Fwd: 5'-AGAGGGCATGGTGGAGATCTT-3' and Rev: 5'-CAAACTCCTCTCCCTGCAGATT-3'; NHE1 Fwd: 5':- AAGGACCAGTTCATCATCGC-3' and Rev:5'- TTCTTCACAGCCAACAGGTC-3'; 18S Fwd: 5'-GGCGTCCCCCAACTTCTTA-3 and Rev: 5'-GGGCATCACAGACCTGTTATT-3'. Assays were performed in triplicate and the RNA expression values were normalized using $18 \mathrm{~S}$ expression and then calculated as fold induction.

\section{Gene silencing experiments}

For the silencing of GPER expression, cells were plated onto $10-\mathrm{cm}$ dishes and transfected using X-treme GENE 9 DNA Transfection Reagent (Roche Diagnostics, Milan, Italy) for 24 hours with two shRNA and two different shGPER. The silencing of GPER expression was obtained by using constructs which we have previously described and used [79]. For knocking down MR expression, cells were seeded in six-well multidishes and transiently transfected the consecutive day at 50\% confluence. For transfection, X-treme GENE 9 DNA Transfection Reagent (Roche Diagnostics, Milan, Italy) was mixed with two small interfering RNAs (siRNA) specific for silencing MR or two siRNA controls (Origene, distributed by Tema Ricerca, Milan, Italy) for 24 hours, prior to treatments.

\section{Western blot analysis}

SkBr3 cells and B-TEC were processed according to a previously described protocol [80-81] to obtain protein lysate that was electrophoresed through a reducing $\mathrm{SDS} / 10 \%(\mathrm{w} / \mathrm{v})$ polyacrylamide gel, electroblotted onto a nitrocellulose membrane and probed with primary antibodies against MR (PA1594) (Boster Immunoleader, distributed by Tema Ricerca, Milan, Italy), phosphorylated ERK 1/2 (E-4), ERK2 (C-14), EGFR (1005), pEGFR ${ }^{\mathrm{Tyr}}$ 1173 (sc-12351-R), GPER (N15), ER $\alpha$ (F10) and $\beta$-actin (C2), all purchased from DBA (Milan, Italy). Proteins were detected by horseradish peroxidase-linked secondary antibodies (DBA, Milan, Italy) and revealed using the ECL System (GE Healthcare). Precision Plus Protein ${ }^{\mathrm{TM}}$ Dual Color Standard (Bio-Rad Laboratories, Milan, Italy) was used to estimate molecular weights and then antigen specificity.

\section{Coimmunoprecipitation}

After stimulation with 10 pM Aldo, SkBr3 breast cancer cells were washed with PBS and lysed using 500 $\mu l$ RIPA buffer with a mixture of protease inhibitors containing $1.7 \mathrm{mg} / \mathrm{ml}$ aprotinin, $1 \mathrm{mg} / \mathrm{ml}$ leupeptin, 200 $\mathrm{mmol} /$ liter phenylmethylsulfonyl fluoride, $200 \mathrm{mmol} /$ liter sodium orthovanadate, and $100 \mathrm{mmol} / \mathrm{liter}$ sodium fluoride. Samples were then centrifuged at 13,000 rpm for $10 \mathrm{~min}$, and protein concentrations were determined using Bradford reagent. Protein $(250 \mu \mathrm{g})$ was then incubated for 2 hours with $900 \mu \mathrm{l}$ of immunoprecipitation buffer with inhibitors, $2 \mu \mathrm{g}$ of GPER, MR or EGFR antibody and 20 $\mu \mathrm{l}$ of Protein $\mathrm{A} / \mathrm{G}$ agarose immunoprecipitation reagent (DBA, Milan, Italy). Samples were then centrifuged at $13,000 \mathrm{rpm}$ for $5 \mathrm{~min}$ at $4^{\circ} \mathrm{C}$ to pellet beads. Pellets were washed four times with $500 \mu \mathrm{l}$ of PBS and centrifuged at $13,000 \mathrm{rpm}$ for $5 \mathrm{~min}$ at $4^{\circ} \mathrm{C}$. Supernatants were collected, resuspended in $20 \mu \mathrm{l}$ RIPA buffer with protease inhibitors, 2X SDS sample buffer (40 mM Tris- $\mathrm{HCl} ; 4 \%$ glycerol; $2 \% \mathrm{SDS}$ ) and $\beta$-mercaptoethanol and heated to $95^{\circ} \mathrm{C}$ for $5 \mathrm{~min}$. Samples were then run on $10 \% \mathrm{SDS}-\mathrm{PAGE}$, transferred to nitrocellulose, and probed with rabbit antiGPER, rabbit anti-MR or rabbit anti-EGFR antibody. Western blot analysis and ECL detection were performed as described above. 


\section{Immunofluorescence and colocalization studies}

$50 \%$ confluent cultured $\mathrm{SkBr} 3$ cells and B-TEC grown on coverslips were serum deprived and then treated for 8 hours with $10 \mathrm{pM}$ Aldo, as indicated. Where required, cells previously transfected for 24 hours with shGPER or siMR and respective control (as described above) and then treated for 8 hours with $10 \mathrm{pM}$ Aldo. Then cells were fixed in $4 \%$ paraformaldehyde, permeabilized with $0.2 \%$ Triton X-100, washed three times with PBS and incubated overnight with a goat primary antibody against NHE-1 (C20) (DBA, Milan, Italy). After incubation, the slides were extensively washed with PBS and incubated with 4',6-diamidino-2-phenylindole dihydrochloride (DAPI), (1:1000), (Sigma-Aldrich, Milan, Italy) and donkey anti-goat IgG-Rhodamine (1:100; purchased from DBA, Milan, Italy). The slides were imaged on the Cytation 3 Cell Imaging Multimode reader (BioTek, Winooski, VT) and analysed using the software Gen5 (BioTek, Winooski, VT).

For colocalization studies $\mathrm{SkBr} 3$ cells seeded on chamber slides were serum deprived for 24 hours and then treated for 15 min with $10 \mathrm{pM}$ Aldo. Next, cells were fixed, permeabilized and incubated overnight with antirabbit GPER (N15) and anti-mouse MR (H10E4C9F) antibodies (DBA, Milan, Italy) alone and in combination. Slides were then incubated with secondary antibodies (donkey anti-rabbit IgG-Rhodamine, DBA, Milan, Italy) and donkey anti-mouse IgG-Fitch (Alexa Fluor, Life Technologies, Milan, Italy), stained by DAPI and then imaged on the Cytation 3 Cell Imaging Multimode reader (BioTek, Winooski, VT).

\section{Proliferation assay}

For quantitative proliferation assay, $\mathrm{SkBr} 3$ cells (1 $\times 10^{5}$ ) were seeded in 24-well plates in regular growth medium. Cells were washed once they had attached and then incubated in medium containing $2.5 \%$ charcoalstripped FBS, transfected for 24 hours, and then treated, as indicated, with transfection and treatments renewed every 2 days. Cells were counted on day 5 using the Countess Automated Cell Counter, as recommended by the manufacturer's protocol (Life Technologies, Milan, Italy).

\section{Migration assay}

Twelve-well plates were coated with $500 \mu \mathrm{L}$ fibronectin for 2 hours at $37^{\circ} \mathrm{C}$ (Sigma Aldrich, Milan, Italy). B-TEC were allowed to grow in regular growth medium until they reached a $70 \%$ to $80 \%$ confluence. Next, cells were incubated in medium containing $2.5 \%$ charcoal-stripped FBS and transfected for 24 hours, as indicated. To create a scratch of the cell monolayer, a p200 pipette tip was used. Cells were then washed twice with PBS and treated. The migration assay was evaluated after 48 hours of treatment.

\section{Time-lapse microscopy}

SkBr3 cells and B-TEC $\left(1 \times 10^{5}\right)$ were seeded in 24-well plates in regular growth medium until they reached a $70 \%$ to $80 \%$ confluence. The culture wells were then incubated in medium containing $2.5 \%$ charcoalstripped FBS, treated and transferred into a time-lapse microscopy platform, equipped with a heated stage chamber (Cytation ${ }^{\mathrm{TM}} 3$ Cell Imaging Multi-Mode Reader, Biotek, Winooski, VT). Cells were maintained at routine incubation settings $\left(37^{\circ} \mathrm{C}, 5 \% \mathrm{CO}_{2}\right)$ using temperature and gas controllers. To evaluate cell proliferation and motility, the images were recorded using Cytation 3 Cell Imaging Multimode Reader and the software Gen5 (BioTek, Winooski, VT) in 10 min intervals for 24 hours (cell proliferation) and 10 hours (cell motility). Then, the images were processed as a movie using the software Adobe Creative Cloud Premier Pro CC. Frames collected every 10 minutes are displayed at a rate of 10 frames s- ${ }^{1}$.

\section{Statistical analysis}

Statistical analysis was performed using ANOVA followed by Newman-Keuls' testing to determine differences in means. $p<0.05$ was considered as statistically significant.

\section{ACKNOWLEDGMENTS}

We thank A. Brossa and N. Fico for the technical support.

\section{COMPETING INTERESTS}

The authors declare that they have no competing interests.

\section{GRANT SUPPORT}

This work was supported by Associazione Italiana per la Ricerca sul Cancro (AIRC grant 16719/2015), Programma Operativo Nazionale "RIicerca e Competitività 2007-2013" (PON 01_01078), Ministero della Salute (grant n. 67/GR-2010-2319511). EMDF was supported by "International Cancer Research Fellowships AIRC-iCARE. 


\section{REFERENCES}

1. Arriza JL, Weinberger C, Cerelli G, Glaser TM, Handelin BL, Housman DE, Evans RM. Cloning of human mineralocorticoid receptor complementary DNA: structural and functional kinship with the glucocorticoid receptor. Science. 1987; 237: 268-275.

2. Meinel S, Gekle M, Grossmann C. Mineralocorticoid receptor signaling: crosstalk with membrane receptors and other modulators. Steroids. 2014; 91: 3-10.

3. Williams JS. Evolving research in nongenomic actions of aldosterone. Curr Opin Endocrinol Diabetes Obes. 2013; 20: 198-203.

4. Krug AW, Grossmann C, Schuster C, Freudinger R, Mildenberger S, Govindan MV, Gekle M. Aldosterone stimulates epidermal growth factor receptor expression. J Biol Chem. 2003; 278: 43060-43066.

5. Paul M, Poyan Mehr A, Kreutz R. Physiology of local renin-angiotensin systems. Physiol Rev. 2006; 86: 747-803.

6. De Giusti VC, Orlowski A, Ciancio MC, Espejo MS, Gonano LA, Caldiz CI, Vila Petroff MG, Villa-Abrille MC, Aiello EA. Aldosterone stimulates the cardiac sodium/ bicarbonate cotransporter via activation of the g proteincoupled receptor gpr30. J Mol Cell Cardiol. 2015; [Epub ahead of print] PMID: 26497404.

7. Amith SR, Fliegel L. Regulation of the $\mathrm{Na}+/ \mathrm{H}+$ Exchanger (NHE-1) in Breast Cancer Metastasis. Cancer Res. 2013; 73: $1259-1264$.

8. Luther JM, Brown NJ. The renin-angiotensin-aldosterone system and glucose homeostasis. Trends Phamacol Sci. 2011; 32: 734-739.

9. Briet M, Schiffrin EL. Vascular actions of aldosterone. J Vasc Res. 2013; 50: 89-99.

10. Calvier L, Miana M, Reboul P, Cachofeiro V, MartinezMartinez E, de Boer RA, Poirier F, Lacolley P, Zannad F, Rossignol P, López-Andrés N. Galectin-3 mediates aldosterone-induced vascular fibrosis. Arterioscler Thromn Vasc Biol. 2013; 33: 67-75.

11. Bienvenu LA1, Morgan J, Rickard AJ, Tesch GH, Cranston GA, Fletcher EK, Delbridge LM, Young MJ. Macrophage mineralocorticoid receptor signaling plays a key role in aldosterone-independent cardiac fibrosis. Endocrinology. 2012; 153: 3416-3425.

12. King S, Bray S, Galbraith S, Christie L, Fleming S. Evidence for aldosterone-dependent growth of renal cell carcinoma. Int J Exp Pathol. 2014; 95: 244-250.

13. Kaji K, Yoshiji H, Kitade M, Ikenaka Y, Noguchi R, Shirai Y, Yoshii J, Yanase K, Namisaki T, Yamazaki M, Tsujimoto T, Kawaratani H, Fukui H. Selective aldosterone blocker, eplerenone, attenuates hepatocellular carcinoma growth and angiogenesis in mice. Hepatol Res. 2010; 40: 540-549.

14. Maggiolini M, Picard D. The unfolding stories of GPR30, a new membrane-bound estrogen receptor. J Endocrinol.
2010; 204: 105-114.

15. Prossnitz ER, Barton M. The G-protein-coupled estrogen receptor GPER in health and disease. Nat Rev Endocrinol. 2011; 7: 715-726.

16. Barton M. Position paper: The membrane estrogen receptor GPER —Clues and questions. Steroids. 2012; 77: 935-942.

17. Filardo EJ, Thomas P. Minireview: G protein-coupled estrogen receptor-1, GPER-1: its mechanism of action and role in female reproductive cancer, renal and vascular physiology. Endocrinology. 2012; 153: 2953-2962.

18. Meyer MR, Prossnitz ER, Barton M. The G proteincoupled estrogen receptor GPER/GPR30 as a regulator of cardiovascular function. Vascul Pharmacol. 2011; 55: 1725.

19. Lindsey SH, Chappell MC. Evidence that the G proteincoupled membrane receptor GPR30 contributes to the cardiovascular actions of estrogen. Gend Med. 2011; 8: 343-354.

20. Prossnitz ER, Maggiolini M. Mechanisms of estrogen signaling and gene expression via GPR30. Molecular and Cellular Endocrinology. 2009; 308: 32-38.

21. Filardo EJ, Quinn JA, Bland KI, Frackelton AR Jr. Estrogen-induced activation of Erk-1 and Erk-2 requires the G protein-coupled receptor homolog, GPR30, and occurs via trans-activation of the epidermal growth factor receptor through release of HB-EGF. Mol Endocrinol. 2000; 14: 1649-1660.

22. Revankar CM, Cimino DF, Sklar LA, Arterburn JB, Prossnitz ER. A transmembrane intracellular estrogen receptor mediates rapid cell signaling. Science. 2005; 307 : 1625-1630.

23. Pandey DP, Lappano R, Albanito L, Madeo A, Maggiolini M, Picard D. Estrogenic GPR30 signalling induces proliferation and migration of breast cancer cells through CTGF. EMBO J. 2009; 28: 523-532.

24. Santolla MF, Lappano R, De Marco P, Pupo M, Vivacqua A, Sisci D, Abonante S, Iacopetta D, Cappello AR, Dolce V, Maggiolini M. G protein-coupled estrogen receptor mediates the up-regulation of fatty acid synthase induced by $17 \beta$-estradiol in cancer cells and cancer-associated fibroblasts. J Biol Chem. 2012; 287: 43234-43245.

25. Vivacqua A, De Marco P, Santolla MF, Cirillo F, Pellegrino M, Panno ML, Abonante S, Maggiolini M. Estrogenic gper signalling regulates mir144 expression in cancer cells and cancer-associated fibroblasts (cafs). Oncotarget. 2015; 6: 16573-16587. Doi: 10.18632/oncotarget.4117.

26. Lappano R, Pisano A, Maggiolini M. GPER Function in Breast Cancer: An Overview. Front Endocrinol (Lausanne). 2014; 5:66.

27. Santolla MF, Avino S, Pellegrino M, De Francesco EM, De Marco P, Lappano R, Vivacqua A, Cirillo F, Rigiracciolo DC, Scarpelli A, Abonante S, Maggiolini M. SIRT1 is involved in oncogenic signaling mediated by GPER in breast cancer. Cell Death and Disease. 2015; 6:e1834. 
28. Santolla MF, De Francesco EM, Lappano R, Rosano C, Abonante S, Maggiolini M. Niacin activates the $G$ protein estrogen receptor (GPER)-mediated signalling. Cell Signal. 2014; 26: 1466-1475.

29. Lappano R, Rosano C, De Marco P, De Francesco EM, Pezzi V, Maggiolini M. Estriol acts as a GPR30 antagonist in estrogen receptor-negative breast cancer cells. Mol Cell Endocrinol. 2010; 320: 162-170.

30. Pupo M, Pisano A, Lappano R, Santolla MF, De Francesco EM, Abonante S, Rosano C, Maggiolini M. Bisphenol A induces gene expression changes and proliferative effects through GPER in breast cancer cells and cancer-associated fibroblasts. Environ Health Perspect. 2012; 120: 1177-1182.

31. Lappano R, Santolla MF, Pupo M, Sinicropi MS, Caruso A, Rosano C, Maggiolini M. MIBE acts as antagonist ligand of both estrogen receptor $\alpha$ and GPER in breast cancer cells. Breast Cancer Res. 2012; 14:R12.

32. Maggiolini M, Santolla MF, Avino S, Aiello F, Rosano C, Garofalo A, Grande F. Identification of two benzopyrroloxazines acting as selective GPER antagonists in breast cancer cells and cancer-associated fibroblasts. Future Med Chem. 2015; 7: 437-448.

33. Sinicropi MS, Lappano R, Caruso A, Santolla MF, Pisano A, Rosano C, Capasso A, Panno A, Lancelot JC, Rault S, Saturnino C, Maggiolini M. (6-bromo-1,4-dimethyl-9Hcarbazol-3-yl-methylene)-hydrazine (carbhydraz) acts as a GPER agonist in breast cancer cells. Curr Top Med Chem. 2015; 15: 1035-1042.

34. Lappano R, Rosano C, Pisano A, Santolla MF, De Francesco EM, De Marco P, Dolce V, Ponassi M, Felli L, Cafeo G, Kohnke FH, Abonante S, Maggiolini M. A calixpyrrole derivative acts as a GPER antagonist: mechanisms and models. Dis Model Mech. 2015; 8: 12371246.

35. Albanito L, Lappano R, Madeo A, Chimento A, Prossnitz ER, Cappello AR, Dolce V, Abonante S, Pezzi V, Maggiolini M. Effects of Atrazine on Estrogen Receptor $\alpha$ - and G Protein-Coupled Receptor 30-Mediated Signalling and Proliferation in Cancer Cells and Cancer-Associated Fibroblasts. Environ Health Perspect. 2015; 123: 493-499.

36. Lappano R, Rosano C, Santolla MF, Pupo M, De Francesco EM, De Marco P, Ponassi M, Spallarossa A, Ranise A, Maggiolini M. Two novel GPER agonists induce gene expression changes and growth effects in cancer cells. Curr Cancer Drug Targets. 2012; 12: 531-542.

37. Funder JW. GPR30, mineralocorticoid receptors, and the rapid vascular effects of aldosterone. Hypertension. 2011; 57: 370-372.

38. Gros R, Ding Q, Liu B, Chorazyczewski J, Feldman RD. Aldosterone mediates its rapid effects in vascular endothelial cells through GPER activation. Am J Physiol Cell Physiol. 2013; 304: C532-540.

39. Brailoiu GC, Benamar K, Arterburn JB, Gao E, Rabinowitz JE, Koch WJ, Brailoiu E. Aldosterone increases cardiac vagal tone via $G$ protein-coupled oestrogen receptor activation. J Physiol. 2013; 591: 4223-4235.

40. Ren Y, D’Ambrosio MA, Garvin JL, Leung P, Kutskill K, Wang H, Peterson EL, Carretero OA. Aldosterone sensitizes connecting tubule glomerular feedback via the aldosterone receptor GPR30. Am J Physiol Renal Physiol. 2014; 307: F427-434.

41. Wendler A, Wehling M. Is GPR30 the membrane aldosterone receptor postulated 20 years ago? Hypertension. 2011; 57:e16.

42. Barton M, Meyer MR. Nicolaus Copernicus and the rapid vascular responses to aldosterone. Trends Endocrinol Metab. 2015; 26: 396-398.

43. Feldman RD, Limbird LE. Copernicus Revisited: Overturning Ptolemy's View of the GPER Universe. Trends Endocrinol Metab. 2015; 26: 592-594.

44. Cheng SB, Dong J, Pang Y, LaRocca J, Hixon M, Thomas P, Filardo EJ. Anatomical location and redistribution of G protein-coupled estrogen receptor-1 during the estrus cycle in mouse kidney and specific binding to estrogens but not aldosterone. Mol Cell Endocrinol. 2014; 382: 950-959.

45. Karmazyn M, Liu Q, Gan XT, Brix BJ, Fliegel L. Aldosterone increases NHE-1 expression and induces NHE-1-dependent hypertrophy in neonatal rat ventricular myocytes. Hypertension. 2003; 42: 1171-1176.

46. Bruder-Nascimento $\mathrm{T}$, da Silva MA, Tostes RC. The involvement of aldosterone on vascular insulin resistance: implications in obesity and type 2 diabetes. Diabetol Metab Syndr. 2014; 6:90.

47. Brown NJ. Contribution of aldosterone to cardiovascular and renal inflammation and fibrosis. Nat Rev Nephrol. 2013; 9: 459-469.

48. Queisser N, Oteiza PI, Link S, Hey V, Stopper H, Schupp $\mathrm{N}$. Aldosterone activates transcription factor Nrf2 in kidney cells both in vitro and in vivo. Antioxid Redox Signal. 2014; 21: 2126-2142.

49. Grossmann C, Husse B, Mildenberger S, Schreier B, Schuman K, Gekle M. Colocalization of mineralocorticoid and EGF receptor at the plasma membrane. Biochim. Biophys. Acta. 2010; 1803: 584-590.

50. Jahn GA, Moguilewsky M, Houdebine LM, Djiane J. Binding and action of glucocorticoids and mineralocorticoids in rabbit mammary gland. Exclusive participation of glucocorticoid type II receptors for stimulation of casein synthesis. Mol Cell Endocrinol. 1987; 52: 205-212.

51. Rabbitt EH, Gittoes NJ, Stewart PM, Hewison M. 11betahydroxysteroid dehydrogenases, cell proliferation and malignancy. J Steroid Biochem Mol Biol. 2003; 85: 415421.

52. Sasano H, Frost AR, Saitoh R, Matsunaga G, Nagura H, Krozowski ZS, Silverberg SG. Localization of mineralocorticoid receptor and 11 beta-hydroxysteroid dehydrogenase type II in human breast and its disorders. 
Anticancer Res. 1997; 17: 2001-2007.

53. Kim CH, Cho YS. Selection and optimization of MCF7 cell line for screening selective inhibitors of 11 betahydroxysteroid dehydrogenase 2. Cell Biochem Funct. 2010; 28: 440-447.

54. De Francesco EM, Angelone T, Pasqua T, Pupo M, Cerra MC, Maggiolini M. GPER mediates cardiotropic effects in spontaneously hypertensive rat hearts. PLoS One. 2013; 8: e69322.

55. Filice E, Angelone T, De Francesco EM, Pellegrino D, Maggiolini M, Cerra MC. Crucial role of phospholamban phosphorylation and S-nitrosylation in the negative lusitropism induced by $17 \beta$-estradiol in the male rat heart. Cell Physiol Biochem. 2011; 28: 41-52.

56. Lappano R, Maggiolini M. G protein-coupled receptors: novel targets for drug discovery in cancer. Nat Rev Drug Discov. 2011; 10: 47-60.

57. Lappano R, Maggiolini M. GPCRs and cancer. Acta Pharmacol Sin. 2012; 33: 351-362.

58. Vivacqua A, Romeo E, De Marco P, De Francesco EM, Abonante S, Maggiolini M. GPER mediates the Egr-1 expression induced by $17 \beta$-estradiol and 4-hydroxitamoxifen in breast and endometrial cancer cells. Breast Cancer Res Treat. 2012; 133: 1025-1035.

59. Lappano R, De Marco P, De Francesco EM, Chimento A, Pezzi V, Maggiolini M. Cross-talk between GPER and growth factor signalling. J Steroid Biochem Mol Biol. 2013; 137: 50-56.

60. De Marco P, Cirillo F, Vivacqua A, Malaguarnera R, Belfiore A, Maggiolini M. Novel Aspects Concerning the Functional Cross-Talk between the Insulin/IGF-I System and Estrogen Signalling in Cancer Cells. Front Endocrinol (Lausanne). 2015; 6:30.

61. Bartella V, De Marco P, Malaguarnera R, Belfiore A, Maggiolini M. New advances on the functional cross-talk between insulin-like growth factor-I and estrogen signalling in cancer. Cell Signal. 2012; 24: 1515-1521.

62. Madeo A, Maggiolini M. Nuclear alternate estrogen receptor GPR30 mediates 17beta-estradiol-induced gene expression and migration in breast cancer-associated fibroblasts. Cancer Res. 2010; 70: 6036-6046.

63. Pupo M, Pisano A, Abonante S, Maggiolini M, Musti AM. GPER activates Notch signalling in breast cancer cells and cancer-associated fibroblasts (CAFs). Int J Biochem Cell Biol. 2014; 46: 56-67.

64. Pupo M, Vivacqua A, Perrotta I, Pisano A, Aquila S, Abonante S, Gasperi-Campani A, Pezzi V, Maggiolini M. The nuclear localization signal is required for nuclear GPER translocation and function in breast Cancer-Associated Fibroblasts (CAFs). Mol Cell Endocrinol. 2013; 376: 23-32.

65. McEneaney V, Harvey BJ, Thomas W. Aldosterone rapidly activates protein kinase D via a mineralocorticoid receptor/ EGFR trans-activation pathway in the M1 kidney CCD cell line. J Steroid Biochem Mol Biol. 2007; 107: 180-190.
66. De Giusti VC, Nolly MB, Yeves AM, Caldiz CI, VillaAbrille MC, Chiappe de Cingolani GE, Ennis IL, Cingolani $\mathrm{HE}$, Aiello EA. Aldosterone stimulates the cardiac $\mathrm{Na}(+) / \mathrm{H}(+)$ exchanger via transactivation of the epidermal growth factor receptor. Hypertension. 2011; 58: 912-919.

67. Morgado-Pascual JL, Rayego-Mateos S, Valdivielso JM, Ortiz A, Egido J, Ruiz-Ortega M. Paricalcitol Inhibits Aldosterone-Induced Proinflammatory Factors by Modulating Epidermal Growth Factor Receptor Pathway in Cultured Tubular Epithelial Cells. Biomed Res Int. 2015; 2015:783538.

68. Fang JS, Gillies RD, Gatenby RA. Adaptation to hypoxia and acidosis in carcinogenesis and tumor progression. Semin Cancer Biol. 2008; 18: 330-337.

69. Martinez-Outschoorn U, Sotgia F, Lisanti MP. Tumor microenvironment and metabolic synergy in breast cancers: critical importance of mitochondrial fuels and function. Semin Oncol. 2014; 41: 195-216.

70. De Francesco EM, Lappano R, Santolla MF, Marsico S, Caruso A, Maggiolini M. HIF-1 $\alpha /$ GPER signalling mediates the expression of VEGF induced by hypoxia in breast cancer associated fibroblasts (CAFs). Breast Cancer Res. 2013; 15:R64.

71. De Francesco EM, Pellegrino M, Santolla MF, Lappano R, Ricchio E, Abonante S, Maggiolini M. GPER mediates activation of HIF $1 \alpha /$ VEGF signalling by estrogens. Cancer Res. 2014; 74: 4053-4064.

72. Recchia AG, De Francesco EM, Vivacqua A, Sisci $\mathrm{D}$, Panno ML, Andò S, Maggiolini M. The G proteincoupled receptor 30 is up-regulated by hypoxia-inducible factor-1alpha (HIF-1alpha) in breast cancer cells and cardiomyocytes. J Biol Chem. 2011; 286: 10773-10782.

73. Rigiracciolo DC, Scarpelli A, Lappano R, Pisano A, Santolla MF, De Marco P, Cirillo F, Cappello AR, Dolce V, Belfiore A, Maggiolini M, De Francesco EM. Copper activates HIF-1 $\alpha /$ GPER/VEGF signalling in cancer cells. Oncotarget. 2015; 6:34158-77. doi: 10.18632/ oncotarget.5779.

74. Barton M, Prossnitz ER. Emerging roles of GPER in diabetes and atherosclerosis. Trends Endocrinol Metab. 2015; 26: 185-192.

75. Feldman RD, Gros R. scular effects of aldosterone: sorting out the receptors and the ligands. Clin Exp Pharmacol Physiol. 2013; 40: 916-921.

76. Brossa A, Grange C, Mancuso L, Annaratone L, Satolli MA, Mazzone M, Camussi G, Bussolati B. Sunitinib but not VEGF blockade inhibits cancer stem cell endothelial differentiation. Oncotarget. 2015; 6: 11295-11309. doi: 10.18632/oncotarget.3123.

77. Grange C, Bussolati B, Bruno S, Fonsato V, Sapino A, Camussi G. Isolation and characterization of human breast tumor-derived endothelial cells. Oncol Rep. 2006; 15: 381386.

78. Fiorio Pla A, Ong HL, Cheng KT, Brossa A, Bussolati B, 
Lockwich T, Paria B, Munaron L, Ambudkar IS. TRPV4 mediates tumor-derived endothelial cell migration via arachidonic acid-activated actin remodeling. Oncogene. 2012; 31: 200-212.

79. Albanito L, Sisci D, Aquila S, Brunelli E, Vivacqua A, Madeo A, Lappano R, Pandey DP, Picard D, Mauro L, Andò S, Maggiolini M. Epidermal growth factor induces $G$ protein-coupled receptor 30 expression in estrogen receptornegative breast cancer. Endocrinology. 2008; 149: 37993808 .

80. De Marco P, Bartella V, Vivacqua A, Lappano R, Santolla MF, Morcavallo A, Pezzi V, Belfiore A, Maggiolini M. Insulin-like growth factor-I regulates GPER expression and function in cancer cells. Oncogene. 2013; 32: 678-688.

81. De Marco P, Romeo E, Vivacqua A, Malaguarnera R, Abonante S, Romeo F, Pezzi V, Belfiore A, Maggiolini M. GPER1 is regulated by insulin in cancer cells and cancerassociated fibroblasts. Endocr Relat Cancer. 2014; 21: 739753. 